

\section{DISCLAIMER}

This report was prepared as an account of work sponsored by an agency of the United States Government. Neither the United States Government nor any agency Thereof, nor any of their employees, makes any warranty, express or implied, or assumes any legal liability or responsibility for the accuracy, completeness, or usefulness of any information, apparatus, product, or process disclosed, or represents that its use would not infringe privately owned rights. Reference herein to any specific commercial product, process, or service by trade name, trademark, manufacturer, or otherwise does not necessarily constitute or imply its endorsement, recommendation, or favoring by the United States Government or any agency thereof. The views and opinions of authors expressed herein do not necessarily state or reflect those of the United States Government or any agency thereof. 


\section{DISCLAIMER}

Portions of this document may be illegible in electronic image products. Images are produced from the best available original document. 


\title{
SAFETY AND RELIABILITY IN SUPERCONDUCTING MHD MAGNETS
}

\author{
C. Laverick ${ }^{\star}$, J. Powell, S. Hsieh, \\ M. Reich, T. Botts, and A. Prodell
}

* Consultant for Brookhaven National Laboratory

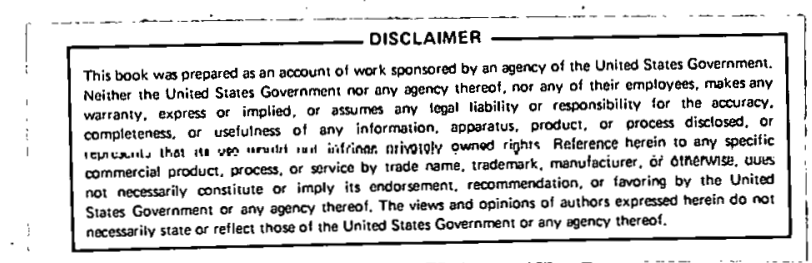

B R O O K H A V E N NA T I O N A L L A B O R A T OR U P T O N, N E W Y O R K 11973 


\section{DISCLAIMER}

This report was prepared as an account of work sponsored by an agency of the United States Government. Neither the United States Government nor any agency thereof, nor any of their employees, nor any of their contractors, subcontractors, or their employees, makes any warranty, express or implied, or assumes any legal liability or responsibility for the accuracy, completeness, or usefulness of any information, apparatus, product, or process disclosed, or represents that its use would not infringe privately owned rights. Reference herein to any specific commercial product, process, or service by trade name, trademark, manufacturer, or otherwise, does not necessarily constitute or imply its endorsement, recommendation, or favoring by the United States Government or any agency, contractor or subcontractor thereof. The views and opinions of authors expressed herein do not necessarily state or reflect those of the United States Government or any agency, contractor or subcontractor thereof.

Printed in the United States of America Available from

National Technical Information Service

U.S. Department of Commerce 5285 Port Royal Road Springfield, VA 22161 
This compilation adapts studies on safety and reliability in fusion magnets to similar problems in superconducting MHD magnets. MHD base load magnet reouirements have been identified from recent Francis Bitter National Laboratory reports and that of other contracts. Information relevant to this subject in recent base load magnet design reports for AVCO - Everett Research. Laboratories and Magnetic Corporation of America is included together with some viewpoints from a BNL workshop on structural analysis needed for superconducting coils in magnetic fusion energy. A summary of design codes used in large bubble chamber magnet design is also included.
\end{abstract}


АВ

TAELE OF CONTENTS $\ldots \ldots \ldots \ldots \ldots \ldots \ldots \ldots \ldots \ldots \ldots \ldots \ldots \ldots \ldots \ldots \ldots$

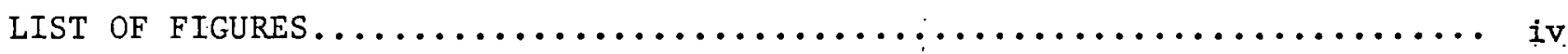

LIST OF TABLES $\ldots \ldots \ldots \ldots \ldots \ldots \ldots \ldots \ldots \ldots \ldots \ldots \ldots \ldots \ldots \ldots \ldots \ldots \ldots \ldots \ldots \ldots$

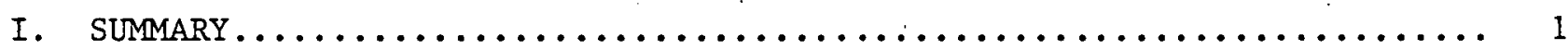

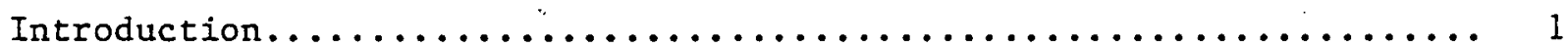

Magnet Requirements................................ 3

Magnet Safety and Reliability Consideration.................. 3

Asperts nf Safetyr and Rodiabiity Dcrived from Magriel Deslyu

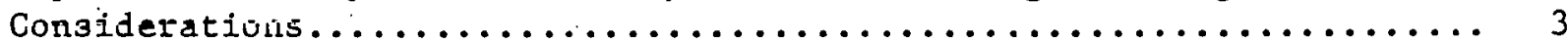

II. SUMMARY REVIEW - SUPERCONDUCTING MHD MAGNET REQUIREMENTS FOR BASE LOAD SYSTEMS ..................................... 6

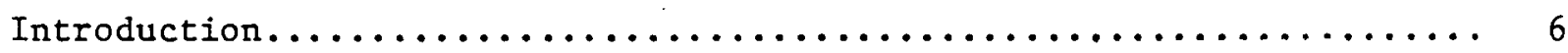

III. A REVIEW OF BNL STUDIES ON SAFETY AND RELIABILITY IN SUPERCONDUCTING TOKAMAK SYSTEM AS THEY MAY APPLY TO SUPERCONDUCTING MHD COILS ....... 18

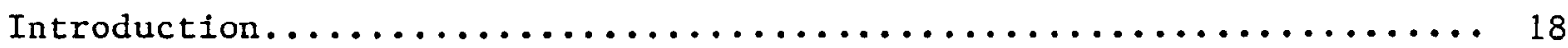

Principal Consideration in Magnet Safety and Reliability........... 19

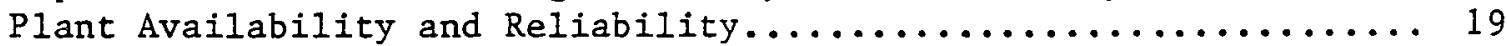

Accident Classifications and Control Strategies................ 19

Structural Analysis - Present Status and Future Needs............. 75

Computer Program Codes for Structural Analysis................. 29

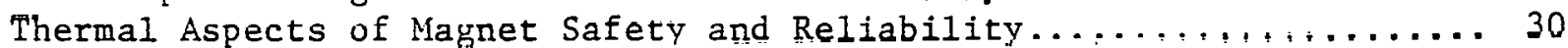

E'lectrical Aspects of Magnet Safety and Reliability ............. 30

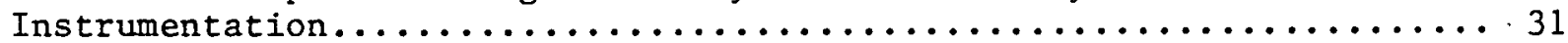

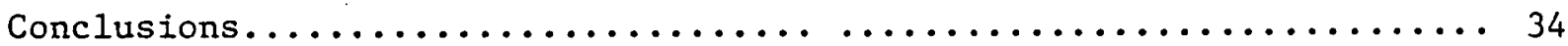

IV. EXTRACTS RELEVANT TO SAFETY, RELIABILITY, AND DESICNN REQUIREMENTS FRCM TEE AVCO 1977 DESIGN STUDY PREPARED FOR ERDA ENTITLED "DESIGN OF SUPERCONDUCTING MAGNETS FOR MHD APPLICATION," BY A. M. HATCH, ET AL...... 40

Design Assumptions and Analytical Tools.................. 40

Winding Geometry Considerations........................ 42

Circular vs Rectangular-Saddle Designs................... 42

Conductor Design, Stability and Current Rating.............. 42

Operating Temperature............................... 43

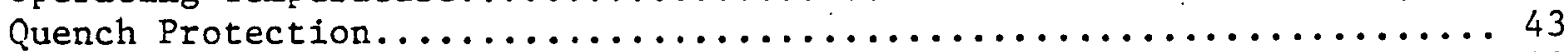

Conclusions and Recomendations...................... 43

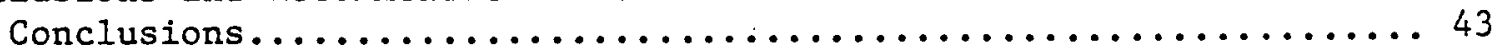

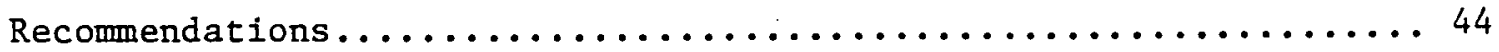


V. EXTRACTS FROM THE MCA DESIGN REPORT RELEVANT TO SAFETY AND RELIABILITY

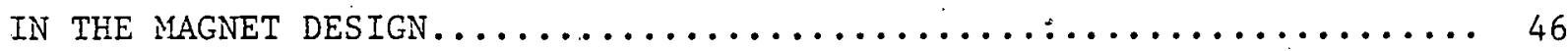

Critical Problems Requiring Investigatton.................. 46

System Operation and Protection......................... 46

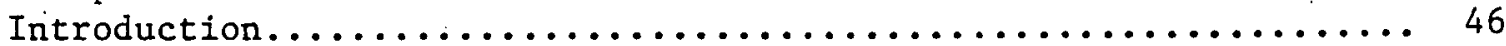

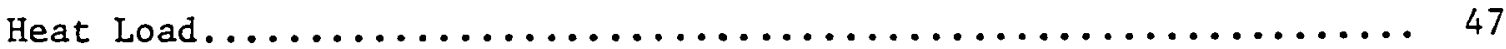

External Cryogenic Support System................... 48

Initial Fill and Vent Lines; Emergency Venting.............. 48

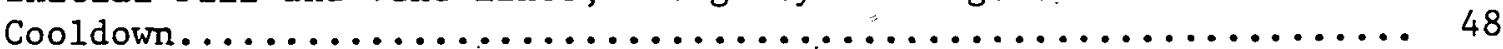

Dishcharge Circuitry and Protection.................... 49

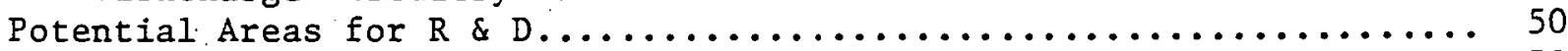

Conductor Properties and Stability Requirements................ 50

Requirements for Stability........................ 50

Impact of High Current Conductor on System Cost............. 52

High Current Conductor Fabrication and Test................ 52

Support for Final Conductor Design.................... 52

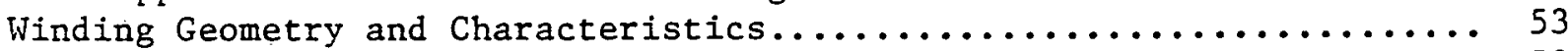

Winding Mechanical and Thermal Characteristics.............. 53

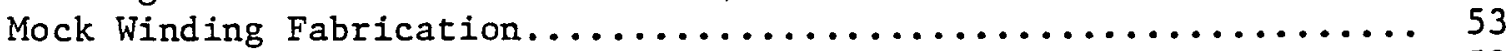

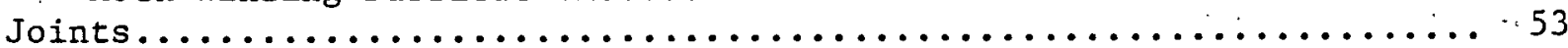

High Current Vapor Cooled Lead Design...................... 53

Insulation Characteristics............................. 54

Loads and structural support.......................... 54

Transverse and End Turn Structure..................... 54

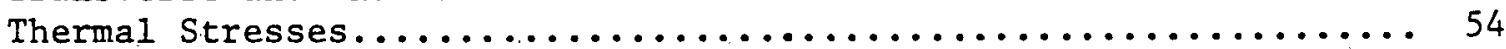

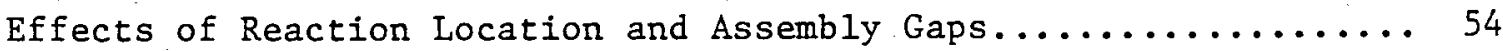

Stress Concentrations at Connectors and Coil Corners..........., 55

Gravitational and Environmental Loads.................. 55

Fault Conditions, Instrumentation, Controls and Interlocks........ 55

Fault Conditions and System Protection.................. 55

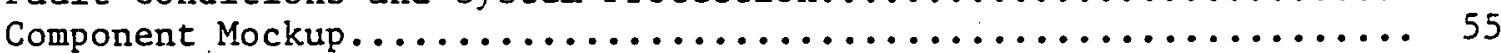

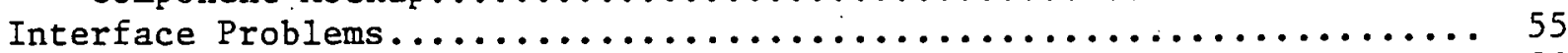

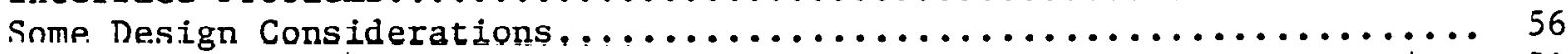

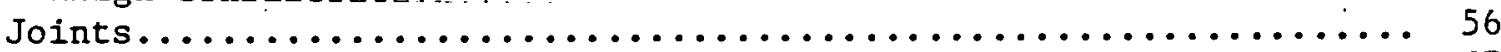

Magnetic Field and Force Calculations.................. 57

Structural Materials.............................. 58

Cryogenic Structural Applications...................... 60

Room Temperature Structural Applications.................. 60

VI. DESIGN CONES APPT.TRART.F TO T.ARGE BUBBLE CHAMBER MAGNETS......... 63

APPENDIX. EDITED EXTRACTS RELEVANT TO MHD MAGNET DESIGN FROM: PROCEEDINGS OF THE WORKSHOP OF STRUCTURAL ANALYSIS NEEDS FOR MAGNETIC FUSION ENERGY SUPERCONDUCTING MAGNETS, M. REICH ET AL. BNL REPORT

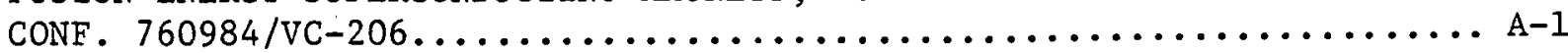


FIGURE I-1 Block Diagram of Base Load Magnet and Support Systems..... 4

FIGURE II-1 CDIF Superconducting Magnet.................... 9

FIGURE II-2 Base Load MHD Magnet Conceptual Design.............. 10

FIGURE II-3 Coil System Assembyly Major Components.............. 14

FIGURE III-1 General Tasks Involved in Assessing Magnet Safety Systems

for .MHD Power Plants......................... 20

FIGURE III-2 Hierarchy of Operating Magnet Safety systems......... 22

FIGURE III-3 Fault Tree for Coil Case Rupture.................. 26

FIGURE III-4 Simplified Fault Tree for Conductor Break........... 27

FIGURE III-5 Simplified Event Tree - Initiator is Conductor Break..... 28

FIGURE 'A-1 Summary of Important Stages Leading to Manufacturing Process of Magnetic Fusion Energy Superconducting............ A-2

FIGURE A-2 Characterization of Magnet Materials in Cryogenic Temperature Range $294^{\circ} \mathrm{K}-4^{\circ} \mathrm{K} \ldots \ldots \ldots \ldots \ldots \ldots \ldots \ldots \ldots \ldots \ldots \ldots \ldots \ldots \ldots \ldots$ 
TAELE II-1 Desirable Parameters for Demonstration and Base Load

page

MED Magnet............................. 7

TABLE .II-2 Selected Superconducting Magnet Parameters............ 8

TABLE III-1 Sumary of Potential Accident Initiators............. 23

TABLE III-2 Characteristics Instrumentation Requirements for Large

Superconducting Coils........................ 33

TABLE III-3 Typical MHD Engineered Safety Features............. 35

TABLE III-4 Summary of Findings on Magnet Safety and Reliability as They Migh Apply to MHD Coils...................... 38

TABLE $\quad \mathrm{V}-1 \quad$ Base Load Magnet Instrumentation List.............. 51

TABLE $\quad V-2 \quad$ Typical Mechanical Properties of Metals.............. 61

TAELE A-1 Input Needed for Theoretical Analysis of the Structural Response of Superconducting Magnets.................A A-3

TABLE A-2 Computed Code in Current Use for Analyzing Complex Mechanical Structure............................A -3

TAELE A-3 Chronology of the Development of Standards for the Nuclear Industry with Some Parallel for Superconducting Magnet Development............................A -8

TABLE A-4 Structure of Development Effort..................A-9 
I. STRAARY

\section{INTRCDUCTION}

This report represents a first step in accumulating opinions and experience on MHD magnet design anc considerations of magnet reliability and safety from which a practical philosophy of safe practice in design, construction, manufacture, inspection and operation may evolve. Far from complete, it hopefully initiates a continuing dialogue. The method adopted has been to compile information from several recent studies, modified in some instances to be relevant to MHD. Basic reports have included the Brookhaven National Laboratory studies on safety and reliability in fusion magnets, MCA and AVCO design studies for Base Load MHD magnets, opinions from a BNL workshop on structural analysis needs for magnetic fusion energy superconducting magnets and safety reports on the Large Bubble Chamber Magnets from which the design codes used in past designs have been identified. A next step would be to use and organize this information to build a checklist for design, construction, testing and safety and reliability analysis and to identify, in a unified manner, the problems to be addressed in producing base load superconducting magnets for MHD plants.

The various parts include a summary review of superconducting MHD magnet requirements for base load systems as they are currently perceived, a review of BNL studies on safety and reliability in superconducting tokamak systems as they may apply to superconducting MHD coils, and relevant extracts from the most recent and pertinent $\mathrm{MHD}$ magnet design reports.

Safety and reliability in superconducting magnet systems begins with conceptual design and should be a factor in all phases of design, prototype development, engineering test programs, commercial demonstrations, and commercial application. Apart from the obvious need to protect people from injury, central electric power/plants are very expensive making excessive downtime costly. This is an important point to remember since the most economic engineering design from the point of view of first cost may not prove to be the most economic over flant lifetime if the capacity factor is low. Sacrifice of reliability to minimize first cost can be expensive. Annual capacity factors for the electrical industry are currently around $65 \%$ which means that two plants have to be available to guarantee that one can be operating at any time. In other words, the actual cost per plant is almost double its capital cost and operating expenses. One advantage of MHD plants is claimed to be high operating efficiency which results in the production of more energy for a given amount of basic resource. Proponents of MHD have speculated that about $50 \%$ of all new power plants built by 2000 $A D$ could be MHD giving a possible requirement of 800 GWe of installed MHD capacity at that time. Such plants would have an average efficiency of at least $50 \%$ compared with $20 \%$ average for U. S. power plants in 1960 and, hopefully, $30 \%$ in 1980. In 1972, the electrical industry consumed $22 \mathrm{Q}$ of resource to deliver 5.7 Q of electricity to its consumers for an average efficiency of $26 \%$. Assuming an average efficiency of $30 \%$ for the plants, $4 \%$ of the 10 ss is due to extracting and transporting the basic resource and to transmitting the electric power to the customer. In 1972, one AEC estimate of installed capacity was 2030 GWe. At $65 \%$ capacity factor this would represent 1313 GW yrs. or 39 Q supplied to customers. At $26 \%$ efficiency this would require $150 \mathrm{Q}$ of basic resource for 
the electrical industry alone, and a waste of total resource of 112 Q, i.e., $55 \%$ greater than the total resource consumed for all forms of energy used in the United States in 1972.

If 800 Give of installed MiD capacity were available at an efficiency of $50 \%$ this would represent $520 \mathrm{GW}$ yrs. at $65 \%$ capacity factor supplying $15.5 Q$ in electricity to customers for an average consumption of $33.8 \mathrm{Q}$ of resource (46\% efficiency. assuming $4 \%$ other losses) as opposed to 590 (26\%) with conventional plants, representing a saving of $26 \mathrm{Q}$.

Thus the use of reliable $\mathrm{MHD}$ in $2000 \mathrm{AD}$ would represent a capital cost of $\$ 800 \mathrm{G}$ or more (i.e., assuming $\$ 1 \mathrm{~K} / \mathrm{kW} \mathrm{hr.} \mathrm{in} 1978 \$$ ) and a saving of $260 / \mathrm{yr}$. in basic resource provided that the plants can be reliable and attain average capacity factors of at least $65 \%$.

Loss of 1 unit for one year would represent $8760 \mathrm{GW}$ hrs. At 5 cents $/ \mathrm{kW} \mathrm{hr}$. this would be equivalent to $\$ 438$ million, i.e., $\$ 1.2 \mathrm{M} / \mathrm{day}$. The need for high reliability in the system becomes obvious. One aim in MHD is to achieve operating times approximating to half a year before channels have to be replaced. Two channels would have to be available in parallel so that continuous operation could be achieved during the replacement operation. Ideally is should be possible to split open the magnet along its length to permit its movement to the second channel and its installation around it, although the possibility of sliding channels in and out of the magnet core also exists. Since the presence of the magnet and its cryogenics is an additional complication, very high reliability will be required to achieve $65 \%$ annual capacity factor since the balance of plant is conventional and the need to change channels is evident. Cooldown of such large magnets may take as much as four weeks and changing of channels may take several days. The magnet current has to be reduced to zero prior to work on the changeover and then raised to its operating level when this is complete. Assuming this to take place 3 times/year it would aggregate to 90 cycles over a 30-year life. Hence, fatigue in the structure or coils need not be a consideration. Ninety percent availability in the magnet system would permit 36 days downtime per year. This would not be long enough to open up the coil system for instrument repair or sensor replacement.

One approach would be to minimize sensor replacement by obtaining much information from CDIF and the engineering test facility in order to attempt a base load magnet design with little or no instrumentation and passive protection from inadvertent magnet discharges. One failure of the magnet system or instrumentation requiring access to the conductors or the inside of the helium dewar could realistically require a 3-month shutdown representing a loss of revenue of over $\$ 100$ million for a $1 \mathrm{GW}$ plant and the need to substitute less efficient, more conventional plants which would involve an additional consumption of basic resource of around $0.05 \mathrm{Q}$ (equivalent to more than $\frac{1}{4} \mathrm{GW} \mathrm{yr}$ ). While the exact costs of the basic resources are not available to the writer and cannot be projected so far into the future an equivalent in electrical energy at $1 \mathrm{cent} / \mathrm{kW} \mathrm{hr}$. would be more than 20M\$. It has been customary to use electrical energy prices of $10 \mathrm{mils} / \mathrm{kW} \mathrm{hr}$. in projections of the past few years; however, in New York City for example, rates of 5 cents $/ \mathrm{kW} \mathrm{hr}$. or more are prevalent today.

Thus if extensive shutdowns can be avoided by either ensuring that no magnet system failure can occur over a 30-year life, or by making certain that any failure can be rectified in days or hours (by substitution of duplicate, already 
available equi,ment) such measures should be adopted even though they may appear deceptively expensive in first cost. In concerns of this nature it is necessary to be familiar with overall MHD plant cost, as well as that proportion due to the magnet system, if realistic decisions on design and economics are to be made.

\section{MAGNET REQUIREMENTS}

The block diagram of Figure I-1 shows the basic components of a superconducting MHD magnet system. In addition to the magnet and dewar it includes a dump switch and discharge resistor, power supply, liquid helium storage and liquefier, compressors, gas storage, vacuum pumping equipment, controls and instrumentation. Various levels of reliability are needed for these components. The base load systems described in section II of this repor are smaller than the 1 GWe Base Load systems now being discussed and may represent the ETF, engineering test facility, an earlier step to the larger systems.

As an example of the design considerations involved, relevant portions of the MCA study have been included. More instrumentation might be included in the earlier steps than might be necessary for the final systems. The base load system might be easier to operate and safer with a $50,000 \mathrm{~A}$ or $100,000 \mathrm{~A}$. conductor designed to absorb its own energy in the event of a superconducting to normal transition. Sizes of conductor and insulator might then be more consistent with with normal, conventional, heavy electrical practice and charge and discharge' voltages and times considerably reduced. It should be noted that a d.c. supericonducting magnet is a static device operating in a constant temperature environment. What experience there has been with large bubble chambers has proven the coils to be the most reliable component of the system.

\section{MAGNET SAFETY AND RELIABILITY CONSIDERATION}

Safety and reliability is reviewed in section III as it might apply to superconducting MHD coils. Accident classification and control strategies are discussed, potential accident initiators are summarized and the use of event and fault trees is discussed. Typical fault and event trees as they may apply to MHD magnets are illustrated to show how they are developed and used. As examples possible fault trees leading to coil case rupture and conductor break are shown followed by an event tree which traces possible sequences of events following a conductor break. The section discusses aspects of rellability and safety as those involve structural analysis, thermal and electrical considerations instrumentation and possible engineered safety features and concludes (Table III-4) with a summary of findings on magnet safety and reliability as they might apply to MHD coils.

\section{ASPECTS OF SAFETY AND RELIABILITY DERIVED FROM MAGNET DESIGN CONSIDERATIONS}

The exhaustive and detailed studies of base load MHD magnet design carried out by MCA and AVCO contained many insights which explain more important design considerations and also contained suggestions outlining problem areas and possibilities for further study. Since reliability begins with the design stage and present day knowledge and practice the more important sections relating to such considerations have been extracted from the reports and included as section IV and $V$. These sections are followed (section VI) by a brief summary of design codes applicable to Large Bubble Cliduber Magnets and an appendix 1ndicating the concerns of structural analysts faced with the problems of computing stresses in large superconducting coils and their possible effects. 


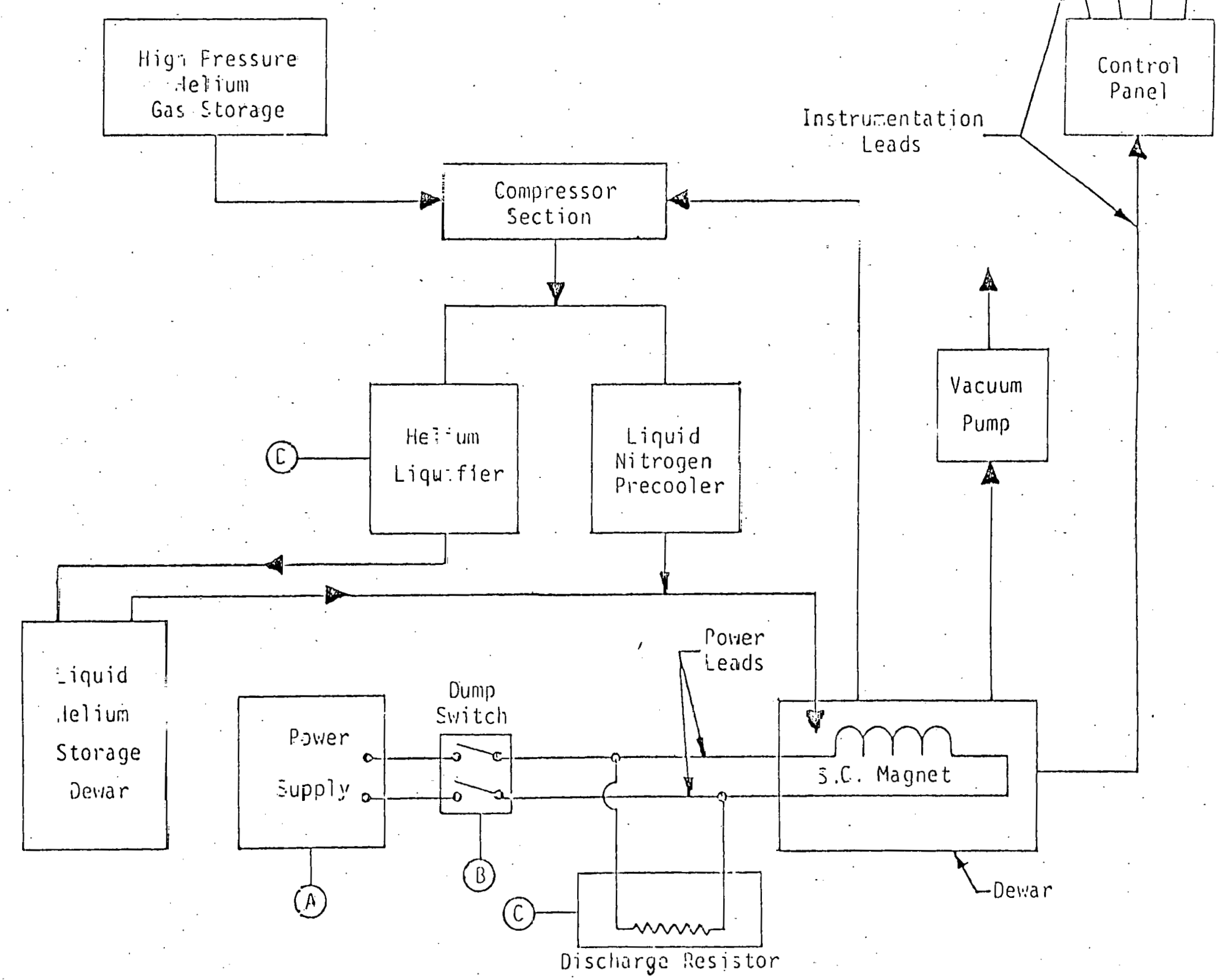

Figure I-1 Block Diagram of Base Load Hannet and Support Systeris 
This approach to the overall problem of design and reliability of necessity contains some repetition and possibly even contradiction but it is a first step in presenting the views of many diverse individuais and organizations confronted with these tasks. A further step would be to organize the material more precisely and develop needed checklists and procedures leading eventually to a formal body of design and construction procedures guaranteeing maximum reliability. 
II. SUMRARY REVIEW - SUPERCONDUCTING MHD MAGNET REQUIREMENTS FOR BASE LOAD SYSTEME

\section{IRTRODUCTION}

A great deal of work has been carried out in recent years to develop superconducting magnets for experimental MHD systems and to study possible favorable options for base load systems. Desirable parameters for base load systems and an engineering test facility have been developed (see Table II-I), and cryostable conductor currents in the range of 50 kiloamperes are now considered desirable to reduce winding effort and charge and discharge voltages. The progression of magnet size and extension of magnet parameters as successive systems are constructed or conceived can be seen from the listing of Table II-2 due to R. C. Neimann. ${ }^{1}$ The basic configuration for a superconducting rectangular saddle magnet for the proposed component design and integration factility (CDIF) can be seen in Figure II-1.

A second type of configuration is that utilizing a circular saddle coil reinforced by rectangular ring girders as shown in Figures II-2 for the base load MiD system. Design studies of superconducting magnets for base load and smaller MHD systems have been carried out by teams involving Magnetics Corporation of America, Avco Everett Research Laboratory, General Dynamics Corporation, and others under the program direction of staff of the Francis Bitter National Laboratory. These studies have been the subject of comprehensive design reports ${ }^{2,3}$ and several conference papers. ${ }^{4,5}$ Some idea of the considerations and of the parameters involved in studying magnet designs of this type can be obtained from the following paragraphs which have been extracted from the MCA study ${ }^{2}$ on a base 'load reference design. This design has an overall length of $26.1 \mathrm{~m}$, an overall diameter of $9.6 \mathrm{~m}$, and a weight of $22.64 \times 10^{5} \mathrm{~kg}$. The system utilizes eight coils which include six racetracks and two of the saddle type. The stucture was based on stainless steel and dewar on aluminum Results of a fabrication study indicated that the major components of the system; i.e., the coil subassemblies, structural components, and dewar components could be fabricated, tested, and preassembled off site and then partially disassembled, shipped and assembled on site.

The major problem which arises is shipment of the large subassemblies to the site. The saddle coil assembly is the largest single component to be transported and has the following overall dimensions and weight: $23.3 \mathrm{~m}$ (76.4 ft.)

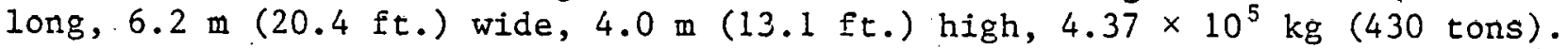
Transportation of a unit of this size is nontrivial but within the present day state of the art using existing equipment or equipment currently on the drawing boards.

The deslgn utilizes copper and NbTi composite superconductor of a type currently being produced in tonnage quantities. As such, the basic building-block for the conductors is readily available today. In addition, the design concepts that are being considered for fabrication do not present any insurmountable manufacturing problems. All processes, equipment and metallurgical requirements are well within present "state of the art" capabilities. Many of the characteristics of the design were generated and determined by consideration of fabrication, handling, shipping and on-site system assembly.

The dewar uses a warm bore with a square cross section. This resulted in a lower conductor amp meter requirement when compared to a round geometry where both cases meet the basic design criteria outlined earlier. 


\section{Principal Focus}

Hinimum Size for Market Penetration 250 Mn (Hin) Muttiple Units

Scalcable (not necessarily optimaliy): Down to ETF

Up to $1000 \mathrm{HW}_{\mathrm{e}}$ (IHHID)

\begin{tabular}{|c|c|c|c|c|c|}
\hline Design Claracteristics & \multicolumn{2}{|c|}{$\begin{array}{l}\text { Deino. } \\
250 \mathrm{MHe}\end{array}$} & \multicolumn{2}{|c|}{$\begin{array}{c}\text { B. L. } \\
500 \mathrm{MH} \\
\end{array}$} & $\begin{array}{c}\text { B. L. } \\
10001.1 U_{e}\end{array}$ \\
\hline Peak on axis field & 6 & 6 & 6 & 6 & 6 \\
\hline Inlet Bore Dimension, square & 2.1 & 2.4 & 2.4 & 2.75 & 2.9 \\
\hline Outiet Bore Dimension, square & 3.9 & 4.3 & 4.9 & 5.4 & 6.5 \\
\hline Active Field Length & 14.5 & 14.5 & 18.7 & 18.7 & 25 \\
\hline Overall Height \& Width & $12.5 \times 12.5$ & $14 \times 14$ & $15.5 \times 15.5$ & $17 \times 17$ & $13 \times 18$ \\
\hline Overall Length & 24 & 24.5 & 31 & 31.5 & 37 \\
\hline Total Weight & 4,000 & 5,200 & 6,800 & 8,500 & 10,000 \\
\hline Stored Energy & 6,500 & 8,300 & 11,000 & 14,500 & 17,000 \\
\hline Dipole Moment $\quad \cdots \quad\left(A m p-M^{2}\right)$ & 30 & 39 & 50 & 64 & 80 \\
\hline Estimated Cost & 69 & 82 & 98 & 117 & 130 \\
\hline$\left(10^{6} \mathrm{NI}\right)$ & 12 & 11 & 47 & 49 & 51.0 \\
\hline $\mathrm{VB}^{2}$ & 2,300 & 3,000 & 3,900 & 5,100 & 5,800 \\
\hline VB ${ }^{2}$ Norm. to U25 & 293 & 382 & 497 & 650 & 712 \\
\hline
\end{tabular}


Table II-2 Sclecied Superconducting Magnet Parameters *

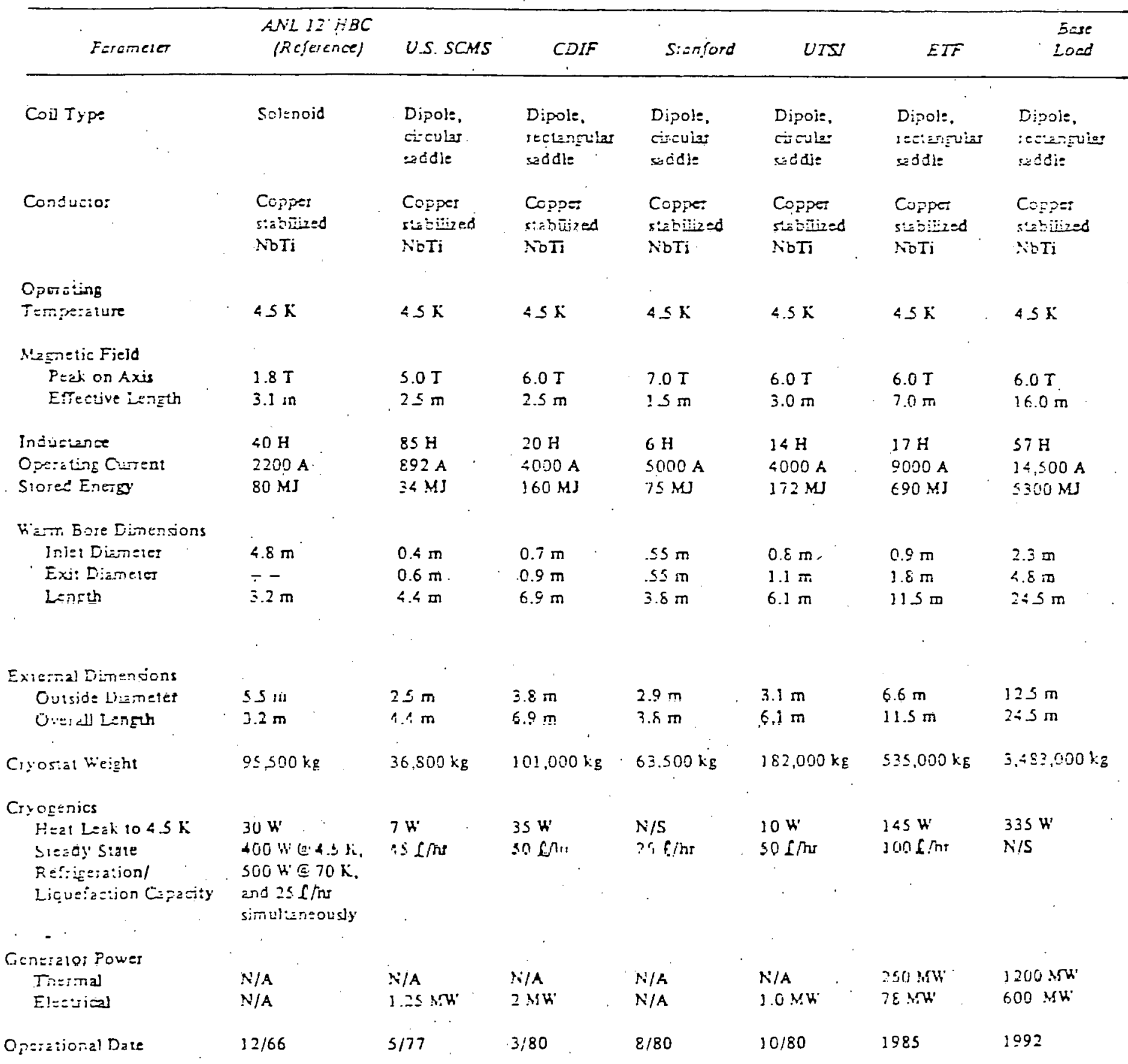

$\dot{x}$. C. Niemann, Superconducing Nagnet System for MHD Generator Facilities, Applications of Cryogenic. Technology, Vo1. 7, pp. 173-194, Scholium International, Inc., 1978. 


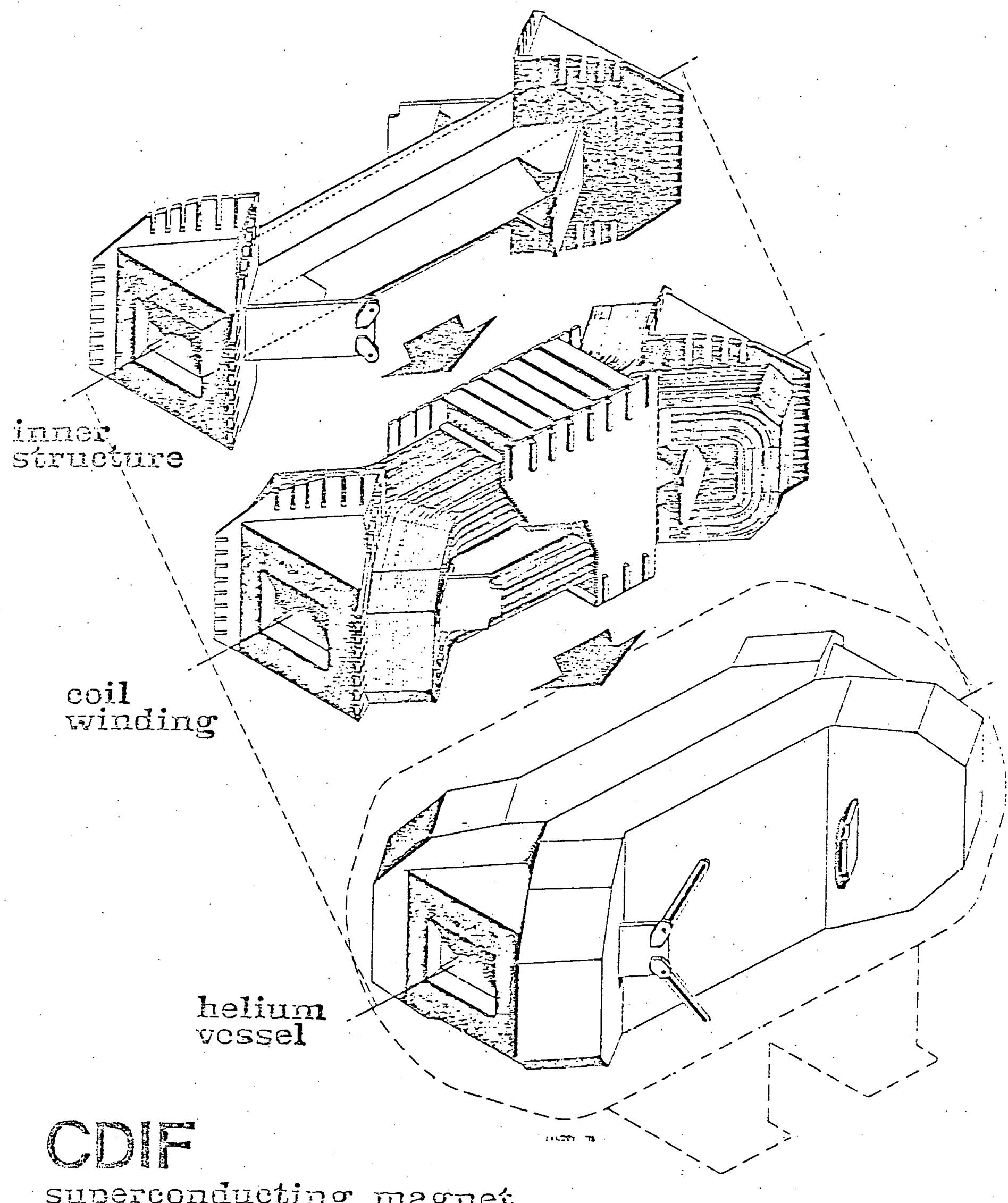

superconducting magnet 


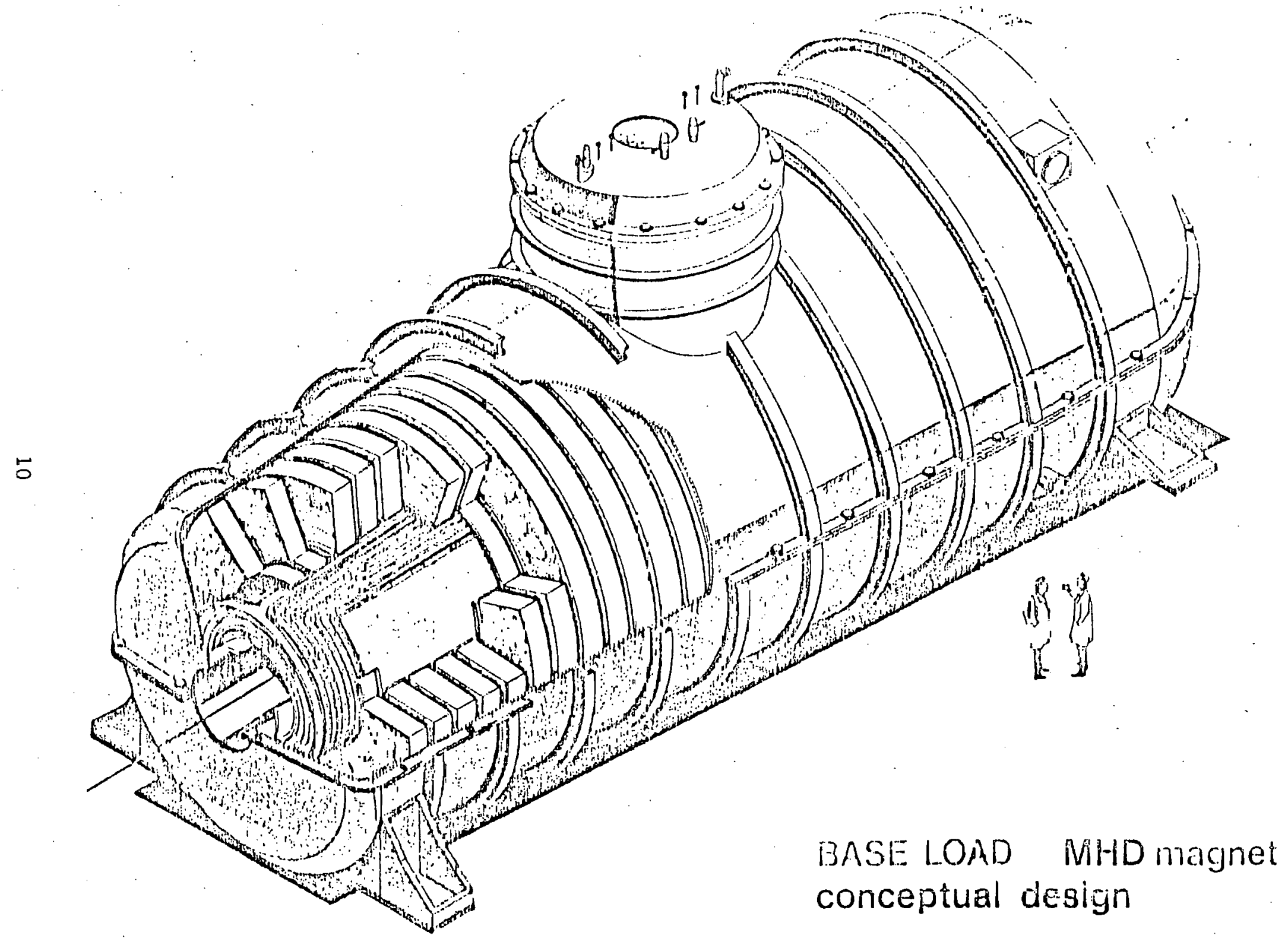

FIGURE II-2 
The magnet operates on 20,000 amps resulting in an overall current density of $1780 / \mathrm{cm}^{2}$. It is estimated that $86.7 \times 10^{3} \mathrm{~m}\left(2.84 \times 10^{5} \mathrm{ft}.\right)$ of conductor are required for the eight ( 8 ) coils in the system. This is indicative of the magnitude of the magnet assembly operation and the manufacturing floor area that will be required to fabricate it. The internal structural weight is greater than the conductor weight, however, both of these items represent a substantial proportion of the total weight.

The system consists of three (3). racetrack coils and one saddle coil per magnet-half. Three sizes of racetrack coils are utilized (i.e., small, medium, and large). They nest within the saddle coils. The coils are designed to operate in the superconducting state at a temperature of $4.5 \mathrm{~K}$ and at a pressure (saturation) somewhat greater than one atmosphere. Structural spacers are located between coils to properly position them and to transmit the forces of electromagnetic (em) origin.

The racetrack coil assembly consists of the coil structure and a liquid helium vessel subassembly, comprised of windings, insulation, interturn structure and a liquid helium vessel. The helium vessel is designed to be vacuum tight to contain the liquid helium while the structure functions to support the em and gravitational loads. The interturn structure transfers the em force through the windings to the coil structure. The coil structure in turn contains these forces. Axial and transverse loads are carried by the top and bottom plates. Tapered plates which are welded to the underside of the assembly are designed to position the coil accurately relative to the other coils and to transfer the attractive forces to the saddle coils. Each racetrack assembly is of a welded and bolted construction and may be shipped to the final site complete and ready for installation.

The basic concept for the saddle coil assembly is similar to the racetrack coil assembly except for the additional external structure that is required to support the transverse and axial em forces. The close proximity of the saddle coil to the warm bore tube negates the possibility for utilization of a simple tension plate apprnach for transverse load support because they would interfere with the warm bore tube. The external structure for transverse load support consists of three (3) basic parts: 1) straight beams, 2) tension plates, and 3). tie rods. The straight beams are fabricated from welded plates and are designed to carry the transverse loads via bending to the tension plates which transmit the load across the magnet: The tie rods are required for assembly purposes and to compensate for the induced couple in the vicinity of the shear stop and end of the plates.

The windings and helium vessel of the saddle coil assembly constitute a coil module (i.e., helium vessel subassembly) which is nested in the structure, similar to the way in which the racetrack coil is assembled. Axial loads are carried by a system of built-up beams and gussets and by axial tie bars which transmit the load from one end to the other.

The dewar is fabricated in two basic components; i.e., the outer dewar, which is composed of the outer vacuum vessel and the radiation shield, and the 
warm bore tube assembly consisting of the warm bore tube and the warm bore radiation shield. Both components also include superinsulation. The outer dewar has been designed in sections to facilitate assembly, maintenance and inspections during operation and for ease of shipping and handling. It is split along the vertical axis. of the magnet to allow it to be pulled aray from the coils and structure to provide free access to all areas of the system. In addition, it has been designed to be disassembled without requiring disconnection of the power leads and coolant lines.

The overall length of the system is $25.3 \mathrm{~m} \mathrm{(83} \mathrm{ft.)} \mathrm{and} \mathrm{the} \mathrm{outside} \mathrm{diameter}$ is $9.6 \mathrm{~m}$ ( $31.5 \mathrm{ft.})$. The maximum height of the assembly to the top of the service stack is $15.6 \mathrm{~m}(51.2 \mathrm{ft}$.$) . The warm bore tube is 1.59 \mathrm{~m}(5.2 \mathrm{ft}$.$) square$ at the inlet and $3.36 \mathrm{~m}$ ( $11.7 \mathrm{ft.}$ ) and square at the outlet. The height from the floor to the MHD channel center line is $6.7 \mathrm{~m}(22 \mathrm{ft.})$. Overall weight of the assembly is estimated to be $22.64 \times 10^{5} \mathrm{~kg}\left(4.98 \times 10^{6}\right.$ 'lbs.).

The main components of the system consist of the following:

1. Coll System and Struclure

2. Dewar

3. Gravitational Support System

4. Cryogenic Piping System

5. Power Lead Assembly

The racetrack coils nest within the saddle coil and are fastened to them with shear stops and high strength bolts. A "magnetic field horizontal" orientation for the coils was chosen for ease of assembly and accessibility.

The dewar consisting of the outer vessel and radiation shield, warm bore tube assembly and the fixed bases is designed such that it can be disassembled for repair, maintenance or inspection purposes. The cylindrical outer vessel and radiation shield consist of two sections each and are "clam shelled" along a vertical line bolted and seal welded joint. Inverted heads which are designed to minimize the exit and entrance length to the MMD channel, are bolted and seal welded to the flanges of the outer vessel and can be removed and reassembled if necessary. The fixed bases are bolted to the concrete floor and contain the valving for the cryogenic systems. The cold can of the service stack is bolted to the cold structure and consequently can remain intact during the dewar disassembly. This means the internal electrical and cryogenic plumbing can be left intact during inspections, repair or maintenarse sitnitions.

The warm bore tube assembly comes from the factory as a complete unit and is designed to be slid in and out of position on rollers and guides which are temporarily located on the saddle colls. In addition, burst discs are provided as necessary in the event of an overpressure situation and access and viewing ports will be utilized.

There are basically three separate cryogenic piping systems. (1) initial fill and vent system, (2) steady state operation fill and vent system, (3) structure coolant system. At initial fill, liquid helium enters through the bottom of each coil and is vented through the top. Each vent contains a throttle valve 
which is used to control the fill transfer rate, and a relief valve which is used to vent the gas in case of an overpressure situation. During operation, liquid helium enters each coil through the top, and also vents at the top, but at the opposite end of the coil. A vent manifold is used to pipe the venting gas to the service stack at which point it is returned to the refrigeration system. Separate coolant lines are provided on the outside surfaces of the structure to control its temperature during cooldown. One service stack is provided on the assembly and contains the liquid helium holdup, the power lead assemblies, the vent line and the fill lines for normal operation.

The coils are connected electrically in series. This is done by routing the current leads for each coil through the initial fill pipes and making the series connections in the service stack. This ensures accessibility and an abundant liquid helium supply. The power leads will be vapor cooled. The helium liquefier delivers liquid directly into the magnet dewar or to a liquid helium storage dewar (which may be an integral part of the main dewar). The purpose of the latter is to provide sufficient liquid capacity to allow magnet operation during maintenance periods for other components of the liquefaction system. Helium gas from the main magnet dewar is fed to the compressors which also receive make up gas from the high pressure gas storage area. The magnet current is provided by a power supply which may be disconnected to allow the magnet energy to dump into a discharge resistor. The purpose of the vacuum pumping system is to allow vacuum testing to be performed at various stages during system assembly and to evacuate the main dewar in preparation for cool-. down. The main control panel allows all major operational parameters to be remotely monitored and provides for control of the system from a remote location.

The major components of the assembly; i.e., the coil assemblies, structural components, and dewar will be fabricated, tested, and preassembled to verify proper fit at off-site manufacturing facilities. The system will then: be partially disassembled into major subassemblies which will be shipped to the site for final assembly and test.

Figure II-3 illustrates the elements that go into a coil/structure subassembly. It begins with the basic building block--the conductor. The conductor, stainless steel internal structure, and insulation materials are then wnund intn shape and ground-wrapped to form the windings. Next, the windings are placed inside the prefabricated liquid helium vessel and the cover of the liquid helium vessel is seal-welded in place to produce the coil module. The coil module is then positioned within the structure and the top cover of the coil module. The coil module is then positioned within the structure and the top cover of the coil structure is bolted into position. This subassembly is referred to as a coil assembly and is completely fabricated off-site. After the trial assembly of all components off-site, the subassemblies are transported to the site for the final system installation. This approach offers the following advantages: (1) the number of parts to be handled on site wich are associated with the superconducting magnet is held to a minimum, (2) the length of time associated with magnet installation is reduced, and (3) the size of the "clean" assembly area required is reduced.

The two saddle windings alone utilize approximately $57 \%$ of the total ampere meters in the system, or roughly $57 \%$ of the conductor weight. This is due to 


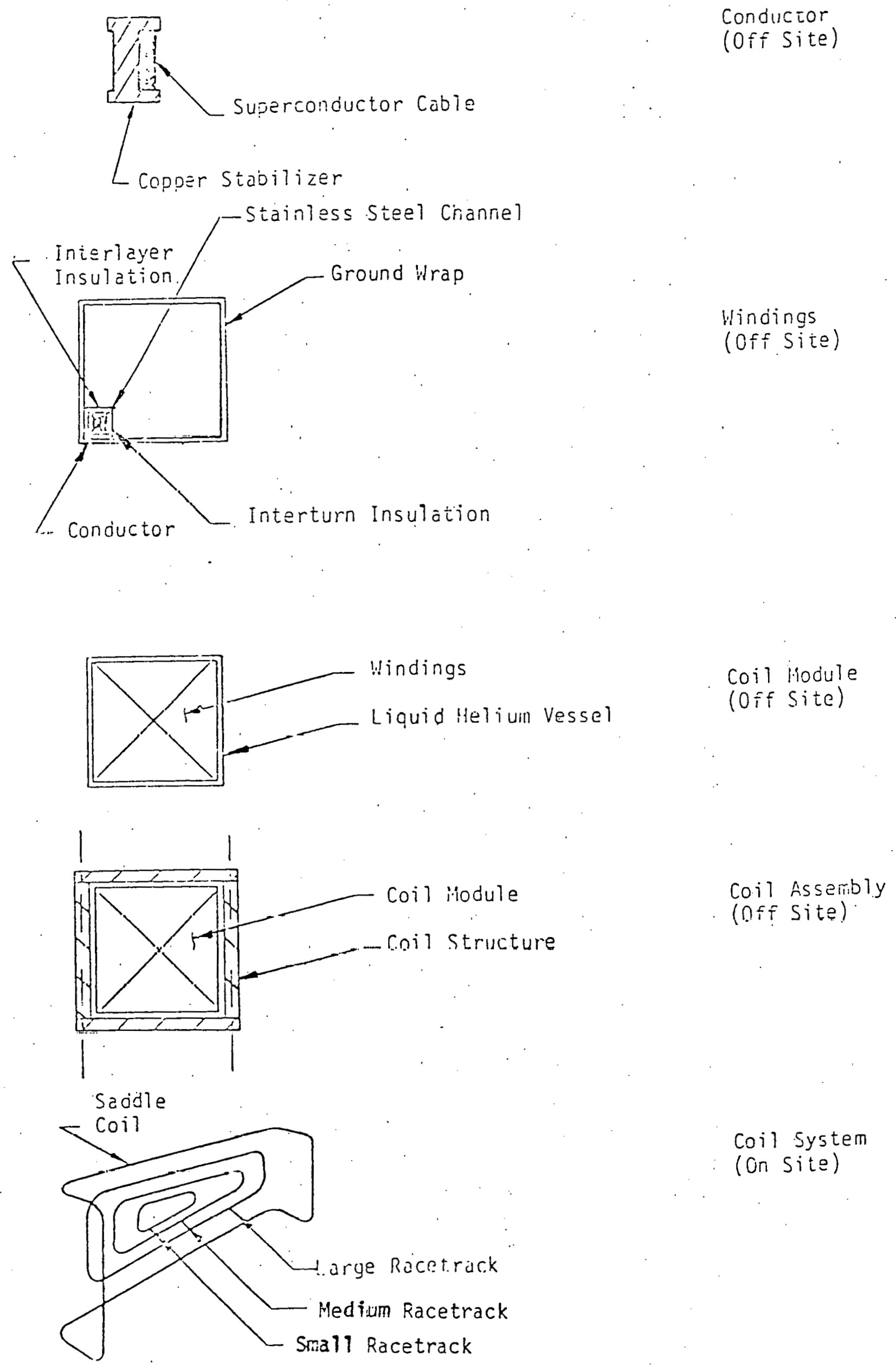

Figure II-3-Coil System Assembly Major Components 
the fact that the saddle windings are in the region where the conductor can be used most efficiently to generate field.

The average overall current density, $\lambda j$, for the Base Load system is a moderate $1,780 \mathrm{~A} / \mathrm{cm}^{2}$. This limitation results from a design criteria which leads tc the use of internal structure within the winding.

Experience with superconducting coil operation in recent years has led to the hypothesis that operational perturbations may result from the temperature rise associated with the heat generated through friction in the event of relative conductor motion. This is a direct result of the low heat capacity of materials at these temperatures and the high turn to turn loads experienced between conductors. Experimental data and criteria in this area are scarce; hence at the outset of this design study the decision was made to utilize an internal support structure around each conductor which would prevent the accumulation of load on the conductors. When design criteria are finally available on an experimental basis, it may well be possible to increase the overall current density somewhat by using internal structure around bundles of conductor rather than around each individual conductor. The approach chosen for this study was believed to be conservative and is attractive from the fabrication standpoint.

The internal structure provides a load path within the winding that eliminates any accumulation of Lorentz forces from turn to turn. The major advantage of this concept is that by isolating each conductor with.its own structure, the bearing stress experienced by any conductor is minimized. This, in turn, minimizes the frictional heating generated in the event of relative conductor motion, since frictional heating is related to the level of bearing stress experienced by the conductor.

Cryostatic stability is a conservative conductor design criterion that requires that the superconductor temperature be limited to its critical temperature even in the event of a complete current transfer from the superconductor to the adjacent stabilizer.

An assumption of the surface heat transfer characteristics for the particular conductor was necessary and was used with the peak field results to determine the amount of conductor stabilizer that would be large enough to limit the conductor temperature.

The total amount of superconductor in the winding was reduced by using a conductor grading scheme that divided the winding bundle into sections and sized the conductor within any particular section according to the maximum field level estimated for that region. Conductor savings in the low field regions were realized in this way.

Three basic conductors were selected for the saddle winding and three were selected for the racetrack windings. The racetrack conductors have an aspect ratio of about 3 to 1 , while the saddle conductors are approximately square so that they can more easily undergo the compound bend that occurs in the end turn region of the saddle winding.

Each conductor consists of a Rutherford type cable conductor and an adjoining copper stabilizer. The conductor stabilizers have $.00127 \mathrm{~m}$ (50 mil) slots on their left and right faces. These are cooling slots that allow the conductor 
to remain in thermal contact with liquid helium along the entire length of the conductor.

Three different Rutherford type cables are used; two for the saddle conductors and another for the racetrack conductors. The cables are composed of $6.8 \times 10^{-4} \mathrm{ml}$ ) $.027 \mathrm{in.}$ ) diameter $45 \mathrm{Nb} 55 \mathrm{Ti}$ superconducting filaments ( $\mathrm{c}: \mathrm{sc}=$ $1.8: 1)$ that are braided together to form a single bundle of superconductors. The bundles are then packed together into the Rutherford type cable.

The cable type conductor is preferred to a monolithic conductor because the extremely long lengths that cable conductor is available in minimizes the number of conductor connections that must be made within the winding. Minimizing the number of joint in turn reduces the fabrication time and the extent of the potentially troublesome joule heating that occurs at joints.

The possibility of using superconducting wire larger than $6: 8 \times 10^{-4} \mathrm{~m}$ (.027 in.) in diameter was considered. However, in terms of present available technology, the $6.8 \times 10^{-4} \mathrm{~m}$ (.027 in.) diameter superconducting wire seemed a better choice for the folliwing reasons. Because a superconductor depends on heat treatment and cold working to atcaln 1ts properties, the cunsilerable amount of cold working that occurs in drawing a wire to this size gives the wire exceptional current carrying ability. Larger wire, on the other hand, cannot achieve as large a current density as the smaller wire. Consequently, for the same current a cable made with large wire will require more superconductor than a cable using small wire. Furthemore, the procedure for manufactuting $6.8 \times$ $10^{-4}$ (.027 in.) diameter superconducting wire is an established technology which Magnetic Corporation of America has used in producing hundreds of thousands of feet of wire.

The effective surface heat flux that the conductors chosen must be able to sustain because of stability considerations is $1.0 \mathrm{~W} / \mathrm{cm}^{2}$. This is believed to be a reasonable design value in light of the results of past measurements on other winding models. Values of about $1.2 \mathrm{~W} / \mathrm{cm}^{2}$ have been achieved, and these are attributed to two- and three-dimensional heat transfer effects.

During the final design study, construction of a winding model for stability testing will be necessary. If the winding measurements indicate that a surface heat flux of $1.0 \mathrm{~W} / \mathrm{cm}^{2}$ is not conservative, then the conductor may be altered to reduce this value.

The amount of additional stabilizer needed to reduce the maximum surface heat flux to $0.8 \mathrm{~W} / \mathrm{cm}^{2}$ results in a substantial increase in the total conductor weight. The $0.8 \mathrm{~W} / \mathrm{cm}^{2}$ conductor requires about $394,000 \mathrm{~kg}$ of conductor, whereas the $1.0 \mathrm{~W} / \mathrm{cm}^{2}$ conductor requires approximately $323,000 \mathrm{~kg}$ of conductor. By using the $1.0 \mathrm{~W} / \mathrm{cm}^{2}$ conductor, therefore, a savings of about $18 \%$ in net conductor weight can be realized. This computes directly into dollar savings in conductor cost.

As described earlier, the internal structure concept that is used is based on providing a means for cumulative load transmittal around each conductor, not through the conductor. This prevents any accumulation of bearing stress from conductor to conductor and this in turn minimizes the frictional heating that can result in the event of conductor motion. 
The main structural element is a channel shaped stainless steel extrusion. Once the conductor is placed into thischannel a stainless steel backing is placed into the remaining space in the channel so that the conductor is encased by stainless steel. A " $B^{\prime \prime}$ staged epoxy impregnated tape $3.81 \times 10^{-4} \mathrm{~m}(15 \mathrm{mil})$ thick that is wrapped around the structure holds the stainless steel backing in place. The wrap also provides turn to turn insulation as well as an interstitial cooling passage between the corductors. 
III. A REVIEW OF. BNL STUDIES ON SAFETY AND RELIABILITY IN SUPERCONDUCTING TOKAMAK SYSTEMS AS THEY MAY APPLY TO SUPERCONDUCTING MHD COILS

\section{INTRODUCTION}

Studies on superconducting magnet safety and reliability as they might re.. late to the toroidal field coils of commercial Tokamak Iusion systems have been carried out at Brookhaven National Laboratory at a modest level of effort over the past few years. This work is summarized in the present paper and modified as it might apply to MHD coils for base load MHD plants. Experience has shown that neglect of issues concerning safety and reliability relating to commercial application during the development stages of a program can result in extensive design readjustment in the final stages with consequent substantial penalties in time and cost for the total program. Thus, while commercial fusion is currently a hope for the far future it is not too early to introduce the subject now. A great deal of experience in these matters has been built up in past years in the electrical industry, heavy industry in general, and, more recently, in the nuclear industry. While guidelines for very large superconducting magnet systems for power plants will probably require the furuulation of completely new and different standards, existing practices and codes can form the basis for outlining approaches to both fusion and MFD systme reliability. These standards would differ for the two cases because magnetic fusion involves radiation and associated hazards while MHD does not.

Little of the past operating and reliability experience with the smaller superconducting magnets of past years will have relevance for the problems ahead in MHD magnet design, operation and maintenance. The combination of very high magnetic loads and large sizes will amplify the structural changes in dimensions, often neglibible in small systems, occurring as a consequence of small thermal gradients due to cool down or to the onset of normal regions in the superconducting composite conductors of the windings during abnormal operating conditions. Again, for the industry, the use of instrumentation at the very low cryogenic temperatures over long and cunlinuuus service represents a new area in which reliability and tailure data is not avallable.

The interaction of safety, reliability, economics, and plant availability also requires further study. In the case of fission reactors, unanticipated changes in commercial plant design attributable in part to safety and environmental considerations has led to increases of a factor of five from initial estimate to final capital cost. Earlier attention to these details in MHD system development may reduce this escalation.

MHD systems require superconducting magnets if they are to be economically acceptable; without superconducting magnets, such systems may not even produce net power.

Results from present coil development programs cannot be expected for some years and data on reliability and maintenance over a decade of operation will not be available before the mid 1990's. Even then, this experience may not be totally relevant for commercial MHD magnets and instrumentation as the test systems are not likely to be operated either as continuously or in the manner required for a commercial system. However the current U.S. policy of enlisting the support of large industrial firms in superconducting magnet development will bring long established practices in "Failure Modes and Effects Analysis," "Safety Analyses," and "Quality Assurance Techniques," to future large coil design. 
By analogy with developments in the nuclear fission industry and its increasing emphasis on quality assurance and safety analysis, both during development and commercial application we can apply this experience and approach in developing a corresponding approach to MHD plants. We identify principal areas of study as being to collect and evaiuate oferational experience from the point of view of safety and reliability, to develop analyses of failure modes and effects, credible events and safety, to assess possible risks and to establish guidelines in quality assurance, design construction, instrumentation, control and operation for fusion magnets.

\section{PRINCIPAL CONSIDERATIONS IN MAGNET SAFETY AND RELIABILITY}

\section{Plant Availability and Reliability}

The most important consideration is to minimize damage to the MHD magnet system so as to maxmize plant availability. Assuming a 30 year plant life an overall availability of $70 \%$ or more is desirable. In this case the overall magnet system consists of the saddle coils, low temperature environment, controls and instrumentation. Thus, plant availability is only partly dependent on saddle coil availability and reliability. An impcrtant question on which the success or failure of this system will turn is: a)"Can the magnet be taken apart in a reasonable time if coil performance is impaired?"

Plant availability is a combination of the Mean Time Between Failure and Mean Time to Repair for the various components of the overall system and the time needed for routine maintenance. These include the saddle coils, the remaining magnet system, and the balance of plant which is mainly conventional. Present day plants, lacking the added complexity of the magnetic systems have availabilities of 65 to $70 \%$ per year. Hence, a very high degree of saddle coil reliability and availability is mandatory because of the fact that even without such systems, present day plant availabilities are barely acceptable. Because of their size and cost, these base plants would be expected to operate at the highest possible annual capacity factor.

Accident Classifications and Control Strategies

By analogy with studies of fission reactor safety, the guidelines developed in assessing accident risks in commercial nuclear power plants could be used as a basis for developing an approach to safety and reliability in MHD systems. This would lead to a diagram such as Figure III-1 which outlines the principal tasks we envisage as being necessary to analyze MHD magnet safety. Three levels of increasing detail and complexity are suggested and are indicated in the diagram by the boundary levels $A, B$, and $C$, where classification $A$ is the least and $C$ the most complex and comprehensive. In class $A$ analyses we identify credible events internal or external to the magnet system which could induce faults, examine containment failure modes and define possible sequences of events by creating event trees. These analyses are quantitative and theoretical and at some later stage should be extended to class $B$ analyses where definition of complete magnet designs, including integration of a variety of safety systems and detailed qualitative examination of all important failure and accident modes will be necessary. Quantitative estimation of failure probabilities and risk assessment, shown in the " $C$ " level boundary, will probably not begin in detail for at least another decade. 


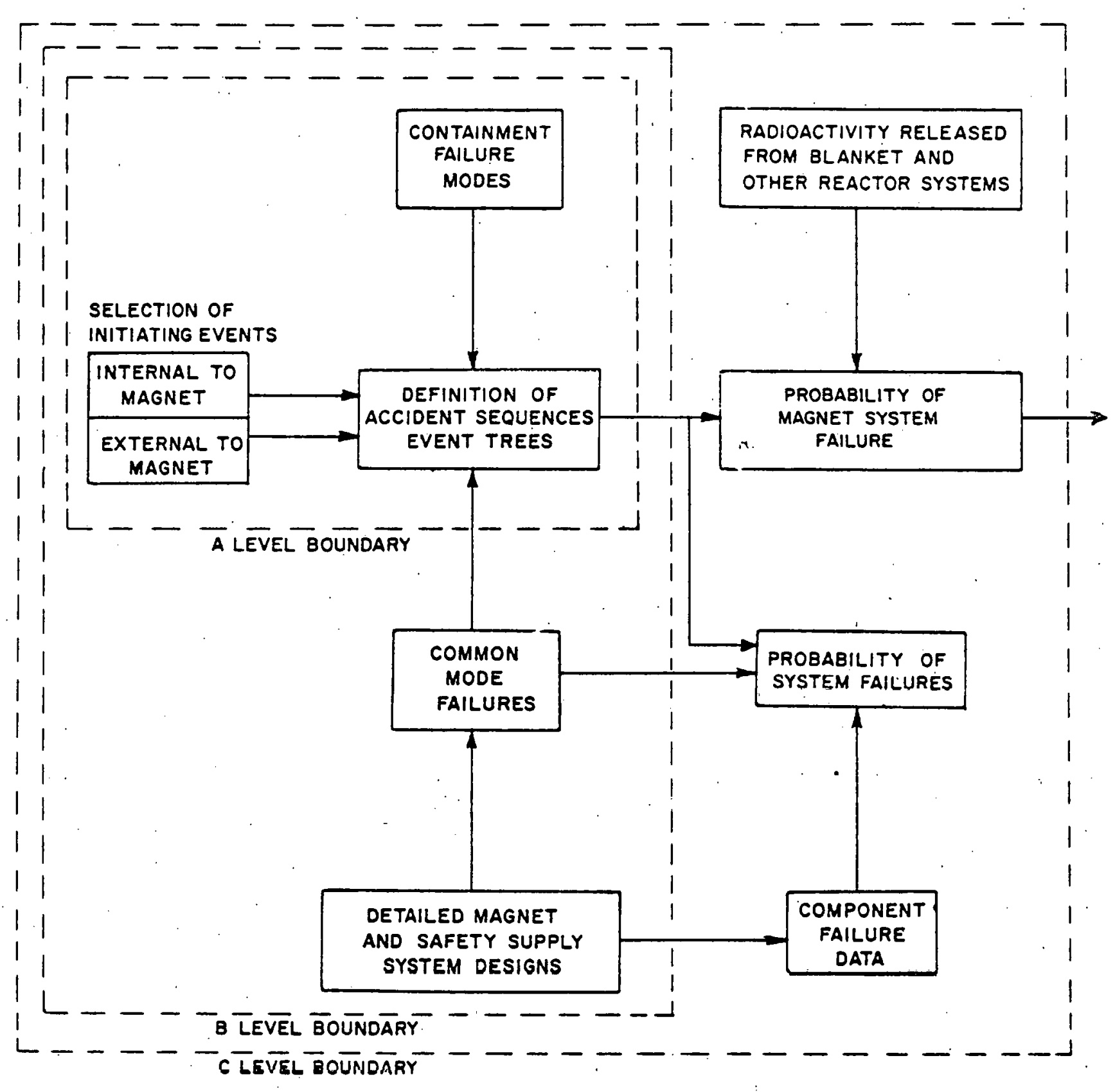

A LEVEL - QUALITATIVE IDENTIFICATION OF IMPORTANT POTENTIAL ACCIDENT EEQUENCES AND ENGINEER SAFETY FEATURES

B LEVEL - QUALITATIVE DEFINITION OF INTEGRATED SAFETY SYSTEMS FOR MAGNETS

C LEVEL - QUANTITATIVE ESTIMATE OF RELIABILITY OF INTEGRATED MAGNET SAFETY SYSTEMS AND RISK ASSESS

\section{FIGURE IIT-].}

GENERAL TASKS INVOLVED IN ASSESSING MAGNET SAFETY SYSTEMS AND RISK ASSESS 
Within these levels of analysis it is possible to develop fault trees and event trees which can be used to anticipate potential operating defects and to develop suitable engineered safety features and operating safety systems to minimize or eliminate their occurrence. In the unlikely event of an operating failure causing system plant shutdown or damage, such analyses and safety systems will be essential. Fault trees can be developed to show the credible pathways that could indicate a given type of failure. Event trees can be used to analyze the possible consequences of this initiating fault on system operation.

Since quantitative failure rate data are virtually nonexistent for superconducting magnet systems, event and fault trees can only be used qualitatively and any assessment of the relative importance of different accident pathways and initiators will be highly subjective.

As event trees presuppose the existence of adequate instrumentation and associated safety features, it is necessary first to consider what a hierarchy of cperating magnet safety systems might include. This is shown in Figure III-2 as it might appertain to an MHD magnet assembly.

A large number of various types of sensors will be required to monitor conditions in the magnet coils and to detect events which can lead to magnet damage or failure. These sensors will have to be interlocked so that they cannot be disconnected without shutting down the plant and will have to be tested frequently to see if they are functioning properly. In addition, sensors will probably have to be redundant to some degree.

The flow of information will probably be too great to be processed by plant operators and may need to be processed by computer. Certain portions of this information would be automatically displayed to the plant operators while other portions would be displayed upon command. Four levels of action are shown in Figure III-2. In level 1 , potentailly serious conditions in the magnet system would be displayed by the computer to alert the plant operators. In level 2, conditions would be judged by the computer to be sufficiently serious that the plant would be shut down and appropriate action taken (temperature equilization, energy removal) to safeguard the magnet. At level 2, the computer actions could not be overridden by plant operators. Level 3 would be an auxiliary level of shutdown and protection that could be triggered by reactor operators if desirable before automatic actions were taken on level 2. Level 4 would correspond to shutdown and protection actions necessary because of safety system malfunction, such as malfunction of the computer or data system.

Whether or not plant operators should override computer actions on level 2 is a difficult question. Studies have shown that in approximately $20-30 \%$ of high stress emergency situations, actions by highly trained individuals either make no difference or make the situation worse. However, on the other hand, the action of experts in avoiding preplanned sequences, either for instrumentation or human operators, have on occasions averted disaster.

As an illustration, we list in Table III-1 some of the possible accident initiators we foresee for $\mathbb{M H D}$ coil systems. Each accident initiator can in turn result in a large number of possible accident pathways, depending on the dynamics of the accident situation, the nature of remedial actions, and the success 
HIERARCHY OF OPERATING MAGNET

SAFETY SYSTEMS

SENSORS

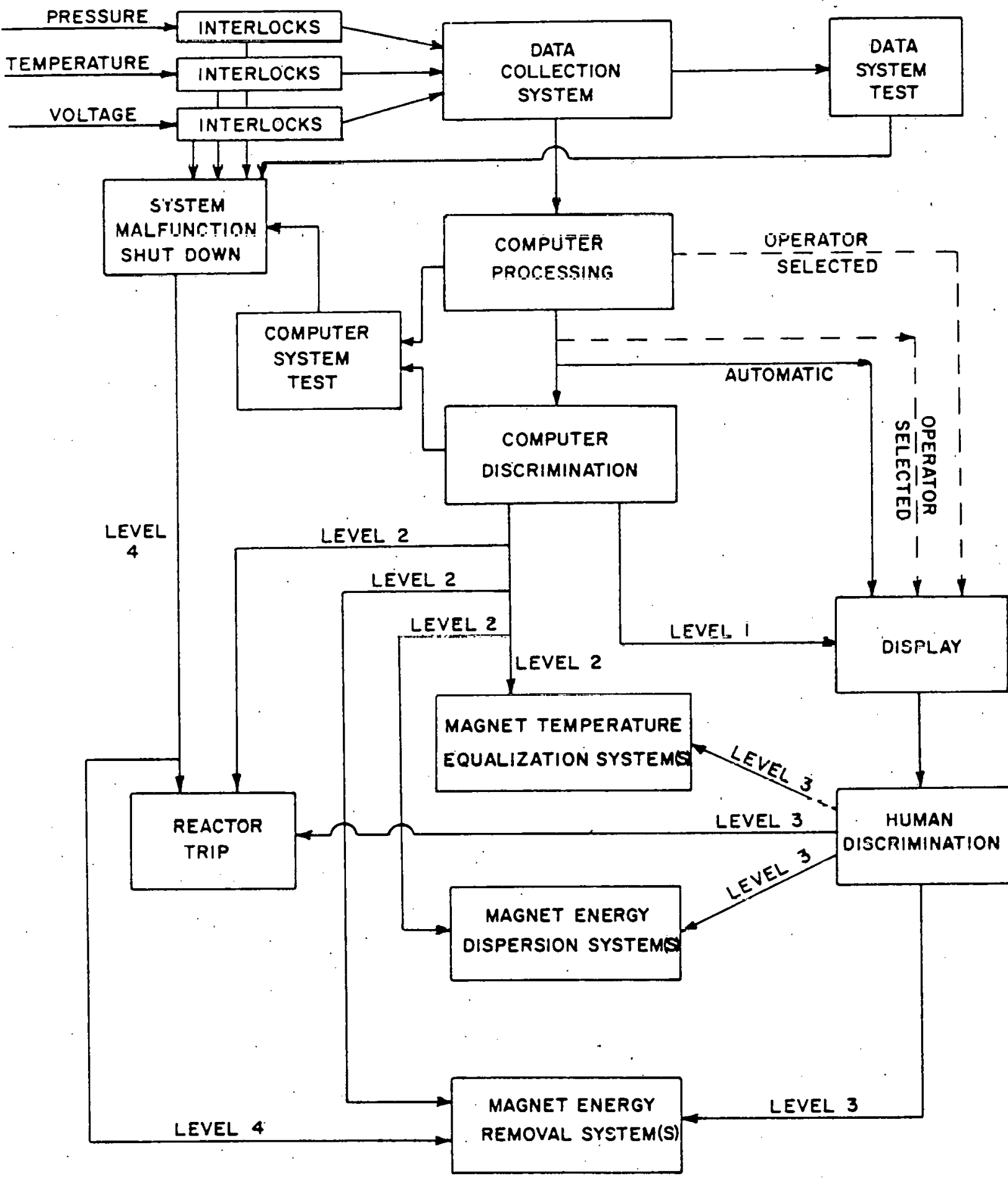

FIGURE III-2 
TABLE III-1-SUMMARY OF POCENTIAL ACCIDENT INITIATORS

Mechanical Initiators Associated with Operation or Assembly of Magnet

Fracture of conductor

- Fracture of reinforcement

- Cracking or plastic deformation of stabilizer resulting in high resistivity

- Fracture of superconductor filamențs (non0cryogenically-stable conductor)

- Excessive conductor movement (glue fractures)

- Crack in insulation

- Rupture of cryostat

Electrical Insulation Initiators (Non-Mechanically Caused)

Metal inclusion in insulator (as fabricated or during assembly)

Metal particle causes bridging between conductor turns

- Excessive voltage during coil dump or quench

- Low dielectric strength of heated helium

- Improper installation of insulation - missing or too thin

Coolant Initiators

- Break of coolant line(s)

- Coolant channel blockage by broken spacer

Summary of Potential Accident Initiators

- Coolant channel blockage by conductor or coil movement

- Coolant channel blockage by collection of impurities from coolant (from refrigerator or other parts of magnet)

Conductor Initiators (Non-Mechanically Caused)

- Impurities or inclusions in stabilizer from ingot or conductor fabrication

- Sudden loss of plasma current

- Magnet charge or discharge too rapid

- Coils pulsed too fast

Lead Initiators

- Fracture of lead

- Inadequate cooling of lead resulting in melting

Initiators External to Magnet System

- Missiles from plant (turbine, coolant line rupture flywheel of energy storage system, etc.)

- Missiles external to reactor plant (airplanes, etc.) 
TABLE III-1 (Continued)

- Earthquakes

- Sabotage

- Human Factor

Control System Malfunction Initiators

- Loss of power to control system

- Failure of sensors

- Failure of interlocks

- Computer malfunction

- Failure of energy dump switching 
or failure of various safety sytems. Our survey of operating experience with superconducting magnet systems constructed to date led to the conclusion that electrical breakdown, conductor breakage, lead failure and coolant channel blockage were major causes of failure.

In the event of a magnet disruption, the primary containment system of the coil could be subjected to the impact of fragments of the conductor traveling at high speed. Such events are not unknown in systems containing large conventional electromagnets. The primary containment for an MAD coil will probably be a system of restraining girders with outer and inner vaculim walls or both.

Detailed analyses should be carried out to determine the effect of missile impact on the primary containment and vacuum walls to design these as to prevent penetration by missiles and if possible, retain leak tightness.

Event and fault trees serve two purposes: a) they qualitatively define the important accident sequences, helping both the designer and safety analyst to visualize readily what potential safety problems exist and what steps may be taken to minimize them; and b) they can be used to estimate the probabilities of various accident sequences if adequate component failure rate data exists. Quantitative information on failure rates of individual components and instrumentation does not yet exist for such large superconducting magnet systems. However, the analysis process can be inverted to provide insight into what upper bounds to compcnent failure rates will be necessary to stay within allowable upper bounds for given accidents. In this process, taking the probability of a given event to be no more than a certain value (say $\leq 10^{-3}$ condcutor breaks per magnet--or plant--year) one can make reasonable estimates of the allowable failure rates in each of the branches of the fault tree. The large number of pathways in the examples developed here leads to two conclusions; comprehensive safety analyses of MHD coils require a large effort, and extensive, reliable engineered safety features will be required.

A typical fault tree is developed in Figure III-3 to illustrate simply the possible pathways leading to rupture of a coil case. A more complex example (see Figure III-4) yet still simplified, traces possible pathways leading to the breakage of a conductor in a coil which has no external support case. Credible events stemming from these faults can be followed in a branching event tree. A typical event tree is given in Figure III-5 for the possibility of conductor breakage. Several other cases have been developed in the BNL study.

\section{STRUCTURAL ANALYSIS - PRESENT STATUS AND FUTURE NEEDS}

Superconducting MHD magnet structures will be made up of complex composites involving superconductors, insulators, stabilizers, structural reinforcements, glues, etc., all of which are interspaced with various types of cooling channel containing liquid or gaseous helium. These structures tend to be more complex than those usually encountered in engineering analysis and sudden local or general heating may take place due to transitions of the superconductors into their normal conducting states. Local movements caused by existing stresses and strains, fracture of the glue or the other magnet components, and fatigue failure of the various materials could cause such transitions. Changing magnetic fields may 
also trigger superconducting to normal transitions directly or by causing local movements of the current carrying conductors. Other events such as coolant channel blockages and externally imposed impulse loads, e.g., earthquakes, missiles, dewar rupture, etc., could also cause such transitions.

Detailed analyses of such magnet structures are beyond the present state of the art unless consicierable simplfying assumptions are made. Structural analysis by itself, no matter how detailed, will be insufficient to fully examine all aspects of magnet safety, but it can predict various material failures that may occur during the operational life. of the magnet so highlighting design problems needing further study. Magnet accident analysis codes for computer programs which consider structural, electrical and heat transfer calculations simultaneously will have to be developed. Such codes can then be used to determine the conditions leading to possible magnet failure modes and their avoidance.

Structures sometimes fail even though the analysis indicates that they should not, due to unusual variations in the properties of commercial materials or unanticipated loads. Designers use empirical safety factors to allow for such uncertainties. In situations where accidents may result in serious consequences, e.g., fission reactors or aircraft, and where the number of variables is very large, $i t$ is very desirable to extend the structural analysis by including meaningful probability of failure to minimum allowable reliability predictions carried out by statistical techniques. These methods should be consistent for MHD magnets.

Complex analytical methods must be verified by closed form solutions, experimental results or both. Very few closed form analytical solutions may exist For the computer codes to be developed for magnet safety studies. Complete verification will require an experimental setup which may have to be fairly complex. These experiments do not necessarily have to be performed on magnet prototypes, but all pertinent physical properties and processes inherent in the magnets must be simulated.

Computer Program Codes for Structural Analysis

Structural analysis of MHD systems can be divided into two classes; (1) analysis for normal operating conditions, and (2) analysis for abnormal and/or accident conditions. Most published analyses have been of the first class and have been restricted to simplifying approximations assuming homogeneous materials: isotropic behavior, and neglect of interlaminar slip between layers of adjacent conditions will probably have more impact on actual CTR magnet system designs.

An approximate understanding of the detailed stresses and strains acting in a heterogeneous magnet structure can be obtained by an analysis of a small portion of the magnet coill using as input boundary conditions the strains or forces obtained from a homogenized analysis of the entire magnet structure. This result is subject to uncertainties since the applied boundary conditions arise from the homogenization approximation. A correct three-dimensional evaluation of the actual heterogeneous structure will probably have to incorporate details regarding the inelastic behavior of the copper in the composite, the sliding and frictional effects of the spacers between the discs, the behavior 
of the plastic spacers in fracture, the inelastic and possibly even (because of the epoxied fiberglass) the orthotropic and fracture mechanics behavior of the glue. Fracture mechanics effects are usually evaluated from one-dimensional tests. For the three-dimensional cases involved in an actual magnet, relating the one-dimensional measurements to the actual design evaluation may be difficult. The effect of high frequency vibraticns on the magnet structure due to gas flow in the MHD channel should also be consistent in case it causes resonances and fatigue effects.

More complex and sophisticated structural analysis methods must be used for the second class of analyses involving non-normal or accident conditions, where melting, large deformations and all types of material failure may have to be simulated under three-dimensional conditions so as to prevent their occurrence in practice. Some of these techniques already exist in various forms, but others will have to be developed and verified by experimental means. The possibility of local failure of glues and insulating spacers due to thermal stresses during unfform quenches should be examined. Any quench should be regarded as a mechanism that could lead to potential coll damage and pussible later failure unless suitable recognition is afforded the problem in the desigr stage.

Seismic analyses of large coils should be carrled out using earthquake input spectra similar to those assumed in fission reactor safety studies to check that the possibility of disruption of the system due to such causes is minimized or eliminated.

\section{THERMAL ASPECTS OF MAGNET SAFETY AND RELIABILITY}

Thermal analyses should be carried out on MFD coils for various assumed initial conditions in a quench so that calculated temperature profiles at various points in the system can be obtained as functions of time after the quench begins. In this way the differentials between various structural and electrical components and their possible effects may be assessed as the coil warms up. These temperature differentials may prove to be sufficient to cause conductor and insulator/glue fracture unless identified and corrected in the designs. Thermal analyses should also be carried out assuming that cooling to a local region is blocked (by insulator deformation, impurity buildup, etc.). In these cases, local temperatures may increase monotonically with time and the heated zone may either remain localized or spread very slowly to the rest of the coil. The propagation rate could be too slow to prevent local conductor melting and. failure. If such local coolant blockage occurs, active safely systems may be needed to detect the blockage and take remedial action in times as short as a few seconds.

\section{ELECTRICAL ASPECTS OF MAGNET SAFETY AND RELIABILITY}

During normal operation the voltages across DC superconducting magnets should be negligibly small so that there is no possibility of electrical breakdown. However, voltages occurring during accident cunditions may be largc enough to cause electrical breakdown and arcing which may lead to rapid melting and failure of a conductor. Such an event could cascade if the total magnet 
energy is then directed to conductors adjacent to the arcing region and coil disruption would be a possibility. If organic insulators are used, hydrogen molecules may be present as frozen free radicals and may migrate quickly into the helium coolant during such an event. A few parts per million of such hydrogen radicals in the warm gaseous helium could lower its already low breakdcwn: strength thus causing electrical breakdown. for very low internal coil voltages.

Relatively small temperature inhomogeneities in magnets undergoing a quench may also produce substantial voltages between coil sections which could cause coil breakdown if not adequately taken into account during design.

\section{INSTRUMENTATION}

Instrumentation is very important. This is a new technology area for industry in which experience and background information is limited. Many sensors may have a short life compared to the 30-year design life of commercial coils since commercially available sensors will of necessity have to be used to avoid a large, long-term development effort. Redundancy of sensors may therefore be desirable.

Instrumentation in the form of quench detection; sensing of thermal, mechanical, or hydraulic changes; monitoring of superconductor performance; and refrigeration plant operation is vital to the safety and routine operation: of the very large and complex systems cuntaining superconducting components ncw heing planned.

We are alreedy entering an era of increasing sophistication in superconducting magnet system designs. Thus, one company has already incorporated its first microprocessor production and control into a large superconducting magnet system. The principal laboratories involved in high energy accelerator applications of superconducting magnets (Brookhaven and Fermi National Laboratories) have developed and used much.more sophisticated electronic monitoring systems for operating large arrays of high current density coils over the past few years. This experience should be extended to MHD magnets as required.

The microprocessor mentioned above controls all interlocks, initiates tests, monitors system parameters, logs errors, initiates alarms and protective sequences and energizes the system correctly. If any cables are not connected, wires broken, or circuits inoperable, the microprocessor locks up the power supply so that the magnet cannot be operated. Provisions are made for power failure. A backup battery system enables the microprocessor to power the system down gently. The microprocessor allows almost complete magnet system operation with little or no user intervention in case of either normal operation or system malfunction.

A further contribution to magnet safety and reliability for future MHD ragnets lies in the various coil specifications developed for the U.S. Large Coil Project (LCP) by Oak Ridge National Laboratory and the coil design studies carried out by the coil contractors in the U.S. and the organizations in Germany, Switzerland and Japan intending to supply individual coils for the test. 
Table III-2 outlines the instrumentation requirements for LCP as they have been specified by Oak Ridge National Laboratory (ORNL). These could well serve as a guide for instrumenting large magnets in general. Accuracy, $3 \mathrm{db}$ bandwidth, and other particulars have been specified as well. Thermometers to monitor cooldown, voltage taps, and displacement transducers along with monitoring helium boil-off or exit are fundamental to reliable magnet operation. Uncertainties remain as to how much more instrumentation will be required in a fusion application. The suppliers have recommended redundancy on many of the sensors.

Instrumentation of LCP performs three services: engineering tests may be monitored; safe, reliable operation may be guaranteed; and some experience may be gained as to the placement and operation of such sensors. In order to accomplish these goals, loss of helium coolant, conductor or structural motion, electrical breakdown, and conductor hot spots are the off-normal events that are. being protected against. All of thses events have characteristic times over which detection must occur for effective coll protection. Analysis of coil designs, treating the density and sorts of instrumentation as variables must be carried out if guarantees of magnet lifetime are to be made. Such analysis is basic to the detailed layout of coll instrumentation.

It is anticipated that no further events are to be detected in further large superconducting coil applications. This implies that the location of sensors, given similar sorts of designs used in LCP will carry over to further applications. Therefore, a careful study of the reliability of LCP sensors, and leads should be carried out. Furthermore, vacuum gauges and sensors to test for off-normal conditions (e.g., elevated temperatures) external to the dewar may need to be added.

LCP relies solely on active coil protection. Based on instrumentation outputs, a decision is made as to whether or not to deposit the coil energy in an external resistor. Passive systems may be employed in future applications to reduce the consequences of an undetected off-normal event and lessen the need for high density, high reliability inserumentation sumewliat.

Degraded states of the magnet, possibly corresponding to a state similar to the half-turn normal, may occur during the operational life of a coil. These allow further operation at the price of decreased coil stability and increased refrigeration requirements. Such states place a greater dependency upon instrumentation and tend to decrease the characteristic time during which evente may be detected. Analysis of such situations will need to be carried out if operation under degraded states is to be carried out successfully.

Instrumertation requirements for some future Tokamak or commercial MitD system may be different in all probability from those for LCP. Here the additional requirement will be to monitor the condition of a coil given its interactions with system components. Of major importance in this situation will be the gathering of sufficient information to declde when it is necessary to shut down the plant and either remove energy from the coil system or absorb this energy in the system. Such energy removal or absorption would be carried out to avoid or minimize magnet damage or damage to other plant systems. In order to minimize false shutdowns, instrumentation must be both reliable and redundant. By imposing the requirement of having at least three to five sensors at each 
Sensor Type

Voltage

Temperature

Strain

Displacement

Field
1 for each double layer or pancake plus 1 , and 1 near ends of the heated zone

40-outside winding cavity or on conductor sheath for cooldown and warmup.

5-to calibrate certain carbon-glass thermometers 4-on current leads 5-inside winding cavity (pool boiling) 4 -inside winding cavity (pool boiling)

32-paired headed zone thermometers In each forced flow helium inlet and outlet line

50-on the structure 24-on conductor or sheath

10-inside winding cavity or internal to coil strusture

4-inside winding cavity

8-in high field region inside winding cavity 4-in high field region inside winding cavity soldered

direct voltage

contact

Pt resistance thermometer

Ge resistance thermometer

carbon-glass thermometer

carbon-resistance

carbon-resistance

cryogenic thermistor

350 ohm strain gauges

120 or $350 \mathrm{ohm}$ strain gauges

spring loaded involving slug displacement transducer

Ball probe

Pick-up coil pick-up coil non-inductively wound copper magnetoresistance probe 
monitoring station instead of only one before action is taken, the total number cf required sensors per coil would be multiplied by three or five as compared with LCP. Furthermore, LCP studies have indicated that internal sensors, Hall probes, strain gauges, etc., are very nearly impossible to replace. Only such sensors as voltage taps and helium level incicators which might be reached through the port on the top of the dewar or vacuum jacket, might be replaceable. Over the possible thirty-years life of a MED power plant sensor replacement may be necessary. If such is the case, either higher redundancy levels or simpler overall configurations of instrumentation may be required. Very high safety margins as in road or rail bridges may be preferable, so eliminating the need for instrumentation and the possibility of instrument or operator error. Over instrumentation may be self-defeating and is no substitute for good engineering design and fabrication.

As the level of instrumentation increases, two different considerations come into play. First, the number of sensors to be monitored increases significantly. Second, as may be witnessed in the LCP preliminary designs, wiring for internal instrumentation is fairly complex. A significant increase in the amount of wiring, especially within the coil pack, may compromise overall magnet system reliability, This being the case, the question arises: What is the optimum level of instrumentation for MHD saddle coils?

Instrumentation of superconducting magnets in future MHD applications is intended as a means of guaranteeing safe, reliable, and effective operation. The following are some observations about the implementation of such instrumentation:

1. LCP instrumentation senses voltage, temperature, conductor strain, conductor displacement, and magnetic field. It would be desirable to know all of these quantities in a future MHD system. Sensors to determine conditions external to the coil (e.g., dewar pressure and ambient temperature) may need to be ardien.

2. Sensors internal to the conductor pack are susceptible to failure if conductor motion occurs.

3. The level of instrumentation and the desirability of replaceable sensors for future Miti coils are areas of importance requiring further study.

4. Characteristic times to detect off-normal situations (e.g., a conductor hot spot) must be determined both for initial magnet conditions and degraded conditions for varying instrumentation densities.

Engineered safety features are required to minimize the chance of coil failure or to minimize its effects if it should occur. At a minimum such features should include those listed in Table III-3.

\section{CONCLUSIONS}

Many potential accident pathways can be visualized for MHD magnets. A quantitative estimation of probabilities is not yet feasible.

- Very low failure rates are required for MHD magnets. 


\section{Sấety Feature}

Derection Systers (DS)

Temperature Equalization Systems' (TES)

Energy netroval Systews (ERS)

Energy Dispersion Systems (EDS)

Containwent Systems (CS)
Function

- Detect local hot spots in coil

- Lead overneating and failure

- Detect arcs in coll

- Detect loss of coolant or flow

- Defect excessive strain or movement

- Drive all conductors nomal early in a quench

- Remove coolant rapidy

- Dump coil energy in external.: resistance

- Prevent excessive local jeposition

- Prevent or minimize coil disruption consequences if coil winding farls 
- Coil disruption accidents may involve local conductor/reinforcement failure with subsequent spreading arcs.

- Conductor arcs and failures should be considered as design basis accidents.

- Most magnet energy may have to be absorbed in the coils to prevent voltage breakdown, unless very high conductor currents and very low inductances are used.

- Temperature differentials must be minimized during a quench, to reduce the chance of local mechanical yielding, electrical breakdown or both simultaneously.

- Electrical breakdown withstand capability may be very limited if a rigid reinforcement structure, acting as a ground plane between magnet terminals, is used,

- lihe ability to detect local not spots (due to cuulanl cllamel luckage, etc.), is desirable. Large number of detectors may be required.

When a coil winding is approximated as a homogeneous structure and analyzed mechanically, complete fallures seem unlikely although local yielding may be conceivable. However, when the actual heterogeneous structure is considered, with its various combinations of conductor, insulator and reinforcement in successive radial or azimuthal layers the possibility of progressive failures through adjacent layers should be studied. The total simultaneous and integrated effect of voltage breakdown, thermal energy deposition and mechanical strain (elastic/ inelastic), should be taken into account in the analysis.

Nonuniform temperature conditions may also cause local structural failure of insulators and/or glues which may not be noticeable when they occur but could act as accident initiators at some later time.

Superconducting. MHD magnet components may fatigue if the operating plant induces resonances in continuous operation. Under these conditions, small flaws in the various magnet components (conductors, reinforcement, insulators, and glues) could grow and eventually cause failure.

Structural analysis capabilities are generally adequate for the gross predictions of the elastic behavior of magnet structures but are not adequate for detailed investigation of the elastic behavior of the actual heterogeneous magnet structures or for the inelastic and fracture mechanics behavior of the actual structures. Coupled thermal-electrical-structural codes are essential for meaningful prediction of magnet behavior during accident situations, but these currently are not available; they need to be developed.

Blocked cooling channels in cryostable conductors operating outside the safe surface formed by the combination of magnetic field, current and supcrconductor temperature may in some instances cause runaway thermal conditions. These may result in rapid temperature rise in localized regions of the conductor and subsequent conductor yielding or even breakage and arcing. The employment of techniques to detect such conditions and take adequate and timely corrective action should be considered. In monolithic designs, the temperature 
differentials between the conductors and the supporting structures in which they are embedded should be kept low enough during abnormal operating conditions to prevent the possibility of the conductors expanding out of the stainless steel supports.

A summary of findings on magnet safety and reliability as they might apply to RHD coils is given in Table III-4. 
MABLE III-4-SUMMARY OF FINDINGS ON MAGNET SAFETY AND RELIABILITY AS THEY MIGHT APPLY TO MHD COILS

Electrical

- Helium is weak link in coils with pool cooling - voltage withstand capability for coils during quenches is $\leq 1000$ volts.

- Rigid metal coil constructions form equipotential surfaces which may permit breakdown between widely separated conductors.

- Voltage withstand capability may be reduced if cracks appear in glue between the conductor jacket and the SS welcled conduits.

- Electrical breakdown is possible in coils duing quenches with relatively small temperature inhomogeneities.

- Technique should be developed to minimize local energy deposition if a coll breakdown resulls in the furmation of a primary arc.

\section{Structural}

- Relatively modest temperature inhomogeneities during quenches can cause local plastic deformation and/or failure of magnet reinforcement and/or conductors.

- Present structural analysis capability must be greatly improved to adequately analyze MHD magnets. Homogenized structure, neglect of interlaminar slip, simplified fracture theory, etc., can cause serious errors, especially for failure evaluation.

- Constitutive relations for complex.structures and material property data are very inadequate.

Quench Situations and Energy Removal

- Breakdown voltages from conductor to ground or between conductor can occur in large superconducting coils during quench or emergency coil discharge unless the combination of insulation, conductor current, composite shunt resistance and coil inductance is well chosen. The $50 \mathrm{kA}$ current planned for base load MHD systems are a well needed step towards safe design. Higher currents, say $100 \mathrm{kA}$ would be safer.

- Large temperature inhomogeneities may occur in some designs during a coil quench, leading to electrical breakdown and mechanical damage, unless the possibility is recognized and avoided for specific designs. Uniform copper per ampere and thermal capacity per ampere arc needed to minimize thermal inhomogeneities in the conductor. 


\section{TABLE III-4 (Continued)}

Detection and Monitoring

- Monitoring of many detection points may be necessary for large magnets. Several redundant detectors/location will be required to ensure reliability. Agreement of at least three detectors will probably be necessary at each sensor station to avoid false alarms. This can be a dilemma since internal instrumentarion in coils and vacuum systems can reduce reliability.

- Detection of localized regions where conductor temperature is monotonically increasing (due to coolant channel blockage, etc.) appears the hardest detection problem.

- Computer monitoring and decision on magnet shutdown appears necessary.

Requirements on Safety and Reliability

- Experience on existing large SC magnets is not sufficient to adequately predict failure rates in large MHD magnets. The technology of existing magnets is much simpler and operating experience too limited. A number of failures have occurred in existing SC magnets, thougn more extensive engineering might have prevented them.

- Extremely low failure rates will be required for MHD magnets in power plants. Judgments as to failure rate will have to be based on analysis since relevant experience will be insufficient for many years.

- A thick external coil case may be desirable to contain the coil if the SC winding fails or to isolate the SC winding from external accidents.

- A very large number of accident pathways can be envisaged for MHD magnets, and it does not appear feasible to quantitatively estimate accident probabilities, at least for the next decade. Only qualitative judgments will be possible. 
IV. EXTRACTS RELEVANT TO SAFETY, RELIABILITY, AND DESIGN REQUIREMENTS FROM. THE AVCO 1977 DESIGN STUDY PREPARED FOR ERDA ENTITLED "DESIGN OF SUPERCONDUCTING MAGNETS FOR MHD APPLICATIONS," BY A.M. HATCH, ET AL.

\section{DESIGN ASSUMPTIONS AND ANALYTICAL TOOLS}

Design assumptions on which designs and calculated values were made included the following:

a) In calculating stresses in ring girders and girder beams, it was assumed that the outward magnetic forces were supported by the girders alone, without any structural assistance from the winding itself, including winding support shells (plates) and other substructures. These will provide some support, and the average stresses in girders will be lower than calculated.

b) In designing low-heat-leak supports, design loads included loads caused by the magnetic interaction of the winding with masses of steel such as bullaling structure outside the magnet assembly (and unsymetrically disposed). These loads were given arbitrary values. For example, for the baseload size magnet, it was assumed that the miximum magnetic load on the winding assembly in the vertical direction would be $30 \%$ of the total weight of the winding and cold structure.

c) In calculating stresses in critical structure components, the effects of stress-raisers such as holes, sharp corners, etc. were neglected. Designs were not sufficiently detailed to warrant local stress analysis. An effort was made to offset this deficiency by designing for relatively conservative "average" stresses.

d) Fatigue effects were not determined analytically in preparing designs, because it was assumed that thermal and force cycling would be moderate and not an important factor in the design of structural parts. It was assumed that thermal cycling (cool-down to $4.5^{\circ} \mathrm{K}$ and warm-up to room temperature) would occur only occasionally during the life of a magnet, (a "worst-case" being perhaps 4 cycles per year), and that cooling and warming would be very gradual. It was further assumed that force cycling due to charging and discharging would generally be at a slow rate (zero to full load in no less than 6 hours).

e) In connection with magnet quench, it was assumed that the helium in the cooling passages throughout the winding would be transformed into a two-phase fluid and this would be rapidly expelled through the vent stack(s), allowing only a relatively small amount of helium to remain in the winding toward the end of the first minute quench. This phenomenon was not analyzed and only rough calculations of pressure rise and lluw rates were made. More carcful andyis of quench boiling and venting should be made as part of any further work applied to the designs covered herein.

Analytical tools used included magnetic field, and finite-element stress analysis computer programs, the latter being applied only to ring-girders. Stresses in structure and windings generally were calculated by hand and represented primarily simple tension, compression and bending stresses. Further information on analytical tools used and future needs in this area is given below. 
Our evaluation of the adequacy and shortcomings of the field and force computations and programs used in computing magnetic fields and forces is as follows.

For the air-core, circular-saddle windings Program JACPACS was very well adapted for calculating fields produced by coils of the geometry used (tapered and "fanned out" saddle coils). This program has been checked against other programs in the past and results found to be in good agreement.

Program JACPACS include a force routine for calculating magnetic forces exerted on the windings (in three dimensions) at various "cuts" around the saddle in one quadrant. The program is reliable for some "cuts" (for example, in the middle of the cross overs and in the straight-section of a single saddle coil). Howevar, the program is not presently set up to handle intermediate cuts in the end turns or single-plane cuts in the straight section of multi-coil windings. Hence, its use for force calculations is limited.

Overa11, JACPACS is a fast, flexible easy to use program that merits further use and upgrading to correct shortcomings.

The program used for computing fields in the rectangular-saddle magnet is believed to be reliable for central (on axis) fields, but is questionable in respect to computed maximum field in the winding. If windings of this general shape are to be studied in more depth, the program should be upgraded to include (or simulate) radii in the cross overs and should be checked for correct ness in computing fields in the winding itself.

Calculations relative to cryostatic stability of windings were simple calculations of heat-flux at cooled surfaces, done by hand or with computer assistance. Likewise, calculations of quench propagation, enhanced by induced-current heating in aluminum alloy substructure, and calculations of magnetic forces on the vacuum jacket (during rapid discharge) were primarily hand calculations to : obtain approximate values.

No analysis was attempted relative to specific motions and frictional heating in the windings and substructure during charging, and the effects on stability.

Stability in large windings should be more fully investigated in the future, taking into account winding and structure design and the nature of mechanical distrubances and friction heating produced. The primary approach in this design study was to provide good structural support for windings, to aim to reduce looseness in the initial "build" and to use conservative heat flux criteria, based on past experience.

Inductance and stored magnetic energy were hand-calculated by methods representing approximations only.

In summary, it is believed that the assumptions and analytical methods used in this program were sufficient for conceptual and preliminary design purposes, and that the designs are therefore basically sound. However, any further work toward more detailed designs should be preceded by upgrading of magnetic field and force programs, by development of analytical methods to account for the structural effect of windings and substructure in partially supporting major magnetic forces and thereby relieving forces on superstructure (ring-girders, etc.), and further $R \& D$ work relative to stability, the nature and effect of motion in windings, quench phenomenon and protective methods. 


\section{WINDING GEOMETRY CONSIDERATIONS}

In large saddle windings, where the winding thickness or "build" is inherently small relative to the inside dimensions of the coil, the peak field at the winding tends to be high relative to the on-axis field and this peak field occurs at the end-turn region. The designs described here are "tapered," with lower fields at exit end, and therefore only the inlet end-turn region is significant when considering peak field.

High peak fields mean high localized pressures in windings and also require high superconductor content in the composite conductor, which increases cost. Because of these factors, it is desirable to mimimize peak field. This can be done by:

a) Increasing the build, with resulting lowering of overall current density.

b) Spreading out (staggering) the end turus, resulting in increased overall length of winding relative to the active length (high field region length).

\section{CIRCULAR VS RECTANGULAR-SADDLE DESIGNS}

The results of the preliminary design effort showed that the circular-saddle design was superior to the (alternate) rectangular-saddle design for the baseload application because it would be cheaper in material and easier to assemble.

\section{CONDUCTOR DESIGN, STABILITY AND CURRENT RATING}

It is logical that a very large magnet be wound with a large, high current conductor in order to avoid an excessive number of turns and the resulting large amount of winding labor involved. Also, high current means relatively low inductance and a lower voltage generated during quench. The value of 1.4,500 amperes, chosen for the preliminary design base-load circular-saddle magnet conductor, was the largest design current practical based on considerations of edge bending and cryostatic stability, for the type of conductor chose (IGC rectangular-cross-section cable type).

The winding design in the base-load circular-saddle magnet could be casily redesigned for higher current and fewer turns in the future, if experience shows that the stability criterion could be less conservative than the value used, which was $0.4 \mathrm{~W} / \mathrm{cm}^{2}$. For example, if it is determined in the future that a heat flux of $0.8 \mathrm{~W} / \mathrm{cm}^{2}$ is satisfactory, the same size conductor could be increased to a design current of about $\sqrt{2} \times 14,500$ amps $=20,500$ amps. The copper to superconductor ratio would be reduced, but otherwise the conductor design would remain essentially the same. With the increased design current, the outside diameter of the winding and of the ring girders could be reduced and the weight of the girders would become considerably less. Inductance would be lower and voltage to ground on quench would be lower. The peak field in the winding wuuld increase somewhat. 


\section{OPERATING TEMPERATURE}

The use of an operating temperature substantially lower than $4.5^{\circ} \mathrm{K}$ although not necessary for any of the magnets studied, would have the advantage of reducing the amount of superconductor (but not necessarily copper) required in a given design with resulting cost savings. However, the cost of refrigeration equipment would be increased and the reliability of the overall system reduced because of the necessity.for operation of external helium piping at less thar atmospheric pressure with accompanying greater risks of contamination.

An example of possible savings in superconductor (NbTi) is as follows: The base-load circular-saddle magnet designed for $4.5^{\circ} \mathrm{K}$ operation contains about $14,700 \mathrm{~kg}$ of $\mathrm{NbTi}$, which at $\$ 70$ per $\mathrm{kg}$ costs about $\$ 1,000,000$. Changing the operating temperature to $3^{\circ} \mathrm{K}$ would reduce the amount of required $\mathrm{NbTi}$ about $35 \%$, making a saving of $\$ 350,000$ in material. This is less than $1 \%$ of the total estimated cost of the magnet. It is believed this saving is not enough to offset the extra cost of lower temperature refrigeration and the extra precautions and risks involved.

\section{QUENCH PROTECTION}

The quench protection scheme incorporates external emergency shunt resistors which initiate a fast discharge of the magnet, a large amount of aluminum sub-structure around the coils and in the polar. regions, inductively coupled to the coils so that circulating currents will be produced in the aluminum by the field change; heating of the aluminum will encourage rapid propagation of the normal region throughout the entire winding. There is the possibility of also incorporating active heaters, or preferably passive shunts acting as heaters which would make more certain the rapid propagation of the normal regions in the magnet. The matter of protection needs further analysis and investigation, not only from the standpoint of dumping energy internally in the coil, but also with regard to the type of sensing system that may be needed to detect a small normal region immediately and automatically activate the circuit breakers which cut in the shunt resistors and initiate the fast discharge.

\section{CONCLUSIONS AND RECOMMENDATIONS}

Conclusions

No critical technological obstacles were encountered in designing the series of magnets reported herein. No novel; unproven features were needed or were incorporated.

For base-load scale and ETF scale magnets up to 6 Tesla central field, sound, practical preliminary designs were developed using cgpper stabilized niobium-titanium conductor bath-cooled and operating at $4.5 \mathrm{~K}$. Extending these designs to produce 7 Tesla central field appeared entirely feasible, using the same type of conductor and operating temperature.

The use of cold iron within the magnet assembly for magnetic field enhancement and shaping offers no overall advantage over a simple aircore magnet design. 
The use of $\mathrm{Nb}_{3} \mathrm{Sn}$ superconductor in large MHD magnets of the magnetic field strengths under consideration ( $5 \mathrm{~T}$ to $7 \mathrm{~T}$ ) is not required and $\mathrm{Nb}_{3} \mathrm{Sn}$ conductor at its present stage of development does not offer overall advantage over the more fully developed, available forms of NbTi superconcductor. However, if and when $\mathrm{Nb}_{3} \mathrm{Sn}$ conductor is developed to have handling characteristics comparable to $\mathrm{NbT} i^{3}$ conductor and a comparable cost, it will be advantageous for large IIHD magnets.

Forced circulation cooled (hollow) conductor, in is present state of development, does not appear to offer advantages over the more conventional bath-cooled conductor as incorporated in the MHD magnet designs presented herein.

The circular-saddle-coil design is superior to the (alternate) rectangularsaddle-coil design as developed in this program, both in respect to utilization of materials and in respect to economy of manufacture. The two designs are believed to be essentially equal from the standpoint of potential reliability.

\section{Recommendations}

A program of applied research and development, laboratory experiments, engineering and manufacturing studies and modeling should be implemented, starting immediately, so that an adequate base of engineering and manufacturing technology for large MHD magnets will be available when needed in the National MHD Power Generation Program. Important objectives of the program will be to improve our understanding of large magnet stability, and means of quench protection, to develop and prove large conductor and conductor splicing, to identify the types of tooling and manufacturing procedures that will be required for manufacturing large magnets, to upgrade designs for greater compatibility with manufacturing techniques and to obtain direct manufacturing and assembly experience with components or models of components of the types contemplated. Specific items which should be included in the program are listed below.

Samples of conductor of the types selected for large MHD magnets should be manufactured and laboratory tested to determine short sample characteristics and also the characteristics of winding sections made of this conductor. (Some scaling down from base-load size may be considered for initial test samples.

Ioints (splices) of types suitable for use with the large MHD magnet conductor should be designed, samples should be made and laboratory testing should be conducted to develop splicing techniques and prove the suitability of splices for use in coils.

Laboratory experiments should be designed and conducted to determine the effect of motion and friction heating on the stability of representative sections of winding of the type to be used in large MHD magnets.

Further analysis and experiments should be conducted to evaluate the protective scheme proposed in this report, involving inductive heating of aluminum alloy winding forms as a means of rapidly driving the entire winding normal, and alternate protective schemes. 
A study should be made of the techniques and equipment required for winding full scale coils. This work should be supported by actual modeling of winding equipment and the making of trial windings using dummy conductors.

Construction technology for selected winding designs shculd be developed by the fabrication of large-scale winding modules (or models the size of the ETF magnet). These models should be made with dummy conductor and there should be two or more winding modules including support structure, assembled together to simulate conditions that would exist in a complete magnet. Mechanical testing should be conducted on these models to determin the amount of conductor motion that may take place under magnetic farces.

Magnetic-field and force computer programs should be upgraded to provide more convenient and accurate output data on magnetic forces and also to calculate the inductance of saddle shaped coils.

A manufacturing feasibility study should be conducted to work out the complete manufacturing procedure for all major components of a base-load size magnet. Coordinated with this, should be a design ufgrading effort in wich the existing preliminary design are modified and improved by inputs from the manufacturing study. 
V. EXTRACTS FROM THE MCA DESIGN REPORT RELEVANT TO SAFETY AND RELIABILITY IN THE MAGNET DESIGN

\section{CRITICAL PROBLEMS REQUIRING INVESTIGATION}

A. Conductor Properties and Stability of Operation

1. Requirements for Stability

2. Impact of High Current Conductor on System Cost

3. High Current Conductor Fabrication and Test

4. Support for Final Conductor Design

B. Winding Geometry and Characteristics

1. Winding Mechanical and Thermal. Characteristics

2. Mock Winding Fabrication

C. Toints

D. High Current Vapor-Cooled Lead Design

E. Insulation Characteristics

F. Loads and Structural Support

1. Transverse and End Structure

2. Thermal Stresses

3. Effects of Reaction Location and Assembly Gaps

4. Stress Concentrations at Connectors and Coil Cornexs

5. Gravitational and Environment Loads

G. Fault Conditions, Instrumentation, Controls, and Interlocks

1. Fault Conditions and System Protection

2. Component Mock-Up

H. Interface Problems

'ithe generation of the reference designs for the BL and ETF magnet systems represents the first step toward final design and construction. Many areas requiring further investigation were uncovered, and $R \& D$ programs should be initiated. No insurmountable englneering problems were uncuvered; heile further. refinement and development of the desigus is in order.

SYSTEM OPERATION AND PROTECTION

Introduction

In a magnet with the amount of stored energy $(\simeq 6,710 \mathrm{MJ})$, and the physical size ( $26 \mathrm{~m}$ long) of the Base Load system, a reliable electrical and cryogenic support system is of paramount importance in assuring the continuous "on-line" operation of the magnet and, in turn, of the MHD generator. Various aspects of 
magnet cooldown and operation will be covered in this section. These include the external cryogenic support system, the cryogenic plumbing within the dewar, initial cooldown considerations, and electrical discharge circuitry. The heat load on the windings, which dictates liquefier system capacity, will be discussed first.

Heat Load

For normal steady state operation of the Base Load system, the heat load that is imposed upon the low temperature windings by the external environment must be absorbed by the cryogenic system. The source of these heat leaks follows.

a. Thermal radiation from the room temperature dewar to the radiation shield (average temperature $102^{\circ} \mathrm{K}$ ).

b. Thermal radiation from the radiation shield to the external winding structure (temperature $4.5^{\circ} \mathrm{K}$ ).

c. Conduction heat transfer through the gravitational support columns to the low temperature external winding structure.

d. Conduction along all instrumentation leads and cryogenic lines that penetrate the room temperature vessel.

e. Conduction and joule heating within the power leads as they penetrate the room temperature dewar.

Although there is no way to eliminate the heat leak to the low temperature. windings, it can be minimized through relatively standard design techniques. The radiation losses will be cut down by using continuous $.0508 \mathrm{~m}$ (2 in.) Iayers of superinsulation in the vacuum gaps on both sides of the radiation shield. All room temperature dewar penetrations will use bellows arrangements or they will help minimize the conduction heat leak. The conduction losses through the support columns are reduced by minimizing this ratio and by using an epoxyglass composite material (high thermal resistance) in the column design.

One. of the major contributors to the heat load is the power leads that penetrate the dewar. The boil off rate for a pair of optimized power leads is about three liters per hour of liquid helium per 1,000 amperes per pair of leads. The boil off rate is a sizeable $60 \mathrm{l} / \mathrm{hr}$. per pair of leads in our case for an operating current of 20,000 amperes. With this amount of boil off per pair of leads, the only way to minimize the heat leak through the leads and thus minimize the refrigeration cost is to penetrate the dewar with a single pair of power leads. The series connections between coils in the system must therefore be made at liquid helium temperature.

The boil off due to all the heat leaks is about $187 \mathrm{l} / \mathrm{hr}$. About $32 \%$ of this is caused by the power leads alone. An additional $15 \%$ was added to allow for instrumentation heat leaks and losses due to unforeseen sources. 
External Cryogenic Support System

The major components of the external cryogenic support system are a twostage screw compressor and helium gas purification system (adsorber), a liquefier (cold box) that utilizes two gas bearing turbo-expanders, a 5,000 \& liquid helium storage dewar, and cryogenic transfer lines between the liquefier and the low temperature vessels. The turbo-expanders, which are inefficient at high temperatures, are bypassed by a liquid nitrogen precooling ionp that utilizes the considerable cooling capacity of a liquid nitrogen bath heat exchanger during the initial cooldown. Since the radiation shield for the magnet will be vapor-cooled by liquid helium boil off and since bulk liquid nitrogen is relatively inexpensive and only needed during cooldown, a separate on-site nitrogen liquefier not warranted.

The helium liquefier should be sized with a capacity that is about $25 \%$ greater than the boil off rate $(187 \mathrm{l} / \mathrm{hr}$.) to provide a safety factor. This will result in a required power input to a conventional liquefier system of about $750 \mathrm{~kW}$. (An advanced design which may be somewhat less reliable would utilize about $375 \mathrm{~kW}$.) Additional cooldown or liquefier capacity can be gained at a later date by adding compressor modules to the system.

Initial Fill and Vent Lines; Emergency Venting

Each coil is filled and vented independently during cooldown by means of a $.1016 \mathrm{~m}$ diameter (4 in.) feed line that is connected to the low point of the coil. A. $2032 \mathrm{~m}$ diameter ( $8 \mathrm{in.}$ ) vent line is located at each end of every coil.

The individual fill and vent lines provide the control needed to maintain a uniform cooling rate amongst all of the coils during cooldown. Uniformity in cooling, in turn, prevents damage induced by thermal stresses. The arrangement of a vent at both ends of each coil is intended to facilitate the control of cooling within an individual coil and to minimize the risk that a preferential flow path might be set up through one leg of a coil. This could lead to severe stress levels within the affected coil.

The vent lines that are used during cooldown have been purposely oversized so that they can handle the vapor discharge that could conceivably result from any coil during a major system failure such as complete loss of vacuum. The vents have been sized so that, for a sonic exit velocity, the entire helium volume in the system can be discharged within one minute. The maximum internal pressure within the winding accompanying this discharge is 30 psia. This is low enough so that no damage should result from the pressure increase relative to normal operating pressure.

The total helium inventory for the system is approximately 24,000 1iters. Cooldown

The cooldown procedure for the Base Load system is as follows:

1) $300-90^{\circ} \mathrm{K}$ : Helium gas is circulated through the liquid nitrogen precooler and is then circulated through the magnet. 
2) Liquefaction is begun. Helium gas is liquefied and then stored in the 5,000 liter storage dewar. A certain amount of the compressor output bypasses the liquefier and continues to maintain the coils near liquid nitrogen temperature with the help of the precooler.

3) $90-20^{\circ} \mathrm{K}$ : Refrigeration continues with the use of the turbo-expanders.

4) $20-4.5^{\circ} \mathrm{K}$ : The liquid helium in the 5,000 1iter dewar is transferred to the magnet while the liquefier continues to operate.

5) Liquid helium is accumulated in the hold-up tank and magnet.

During the cooldown procedure, a separate cold gas cooling loop that bypasses the magnet circulates helium gas around the radiation shield. Normally, the shield is cooled by vapor vented from the coils. However, this is not done during cooldown because very little cooling capacity remains in the gas stream as it leaves the relatively warm coils. Consequently, a warm radiation shield that is ineffective at intercepting the radiative heat load would result and this, in turn, would prolong the cooldown time.

The cold structure external to each coil is primarily conduction cooled through contact with the winding bundles. However, high thermal contact resistances between the external structure and the dewars enclosing each coil may exist since this contact is in vacuum and can extend the structural cooldown time considerably. More importantly, however, the high contact resistances can result in differential contractions between the coils and the cold structure which may induce sizable stresses within the windings. It is possible for the conductor to yield in tension if the winding is cooled considerably faster than the external structure. To combat this problem, cooldown tubing will be included on both the saddle structure and on both large racetracks over their entire length. Because all the cold structure is tied together, the external structure near the small and medium-sized racetracks will feel the effects of these tracer tubes also. The temperature in both the external structure and in the coils" will be monitored and the cooling rates controlled so that an acceptable temperature differential between the coils and the structure is maintained.

When the coil temperature for the small racetrack at a given instant is $100^{\circ} \mathrm{K}$, a structural temperature greater than $132{ }^{\circ} \mathrm{K}$ causes the conductor to exceed its allowable working stress in tension. Information like this can be used during cooldown to minimize the adverse effects of differential contractions in the magnet.

Cooldown estimates for the Base Load system were determined. The result was a projected cooldown time of 14 days. In general, however, many factors that enter into the dynamics of the cooldown process make it hard to accurately model the system. With a magnet of the size of the Base Load system, therefore, one could easily anticipate a cooldown interval of four or five weeks.

\section{Discharge Circuitry and Protection}

A bank of discharge resistors in series is connected across the winding terminals. When it is desired to deenergize the magnet, the dump switch is opened. 
Initially, the energy is dissipated through a single dump resistor, $R_{D}$. (The other resistors are initially shunted by switches $\mathrm{S}_{1}$ through $\mathrm{S}_{\mathrm{N}}$.) A resistance of $.0125 \Omega$ will limit the initial terminal voltage to 250 volts. The initial discharge time constant for the system is then about 45 minutes. As the current level in the winding gradually decays, a second dump resistor is thrown into the circuit by opening switch $S_{1}$. This added resistance increases the decay time constant, and the system discharges at a faster rate. With the layerto-layer voltage being carefully monitored, the decay rate can be accelerated by cutting additional Iesistors into the discharge circuit at intervals consistent will allowable voltage across the coil terminals. Several factors that go into the selection of conductor and the winding design for this magnet preclude the possibility of a complete transition to a resistive condition (quench) during normal operations. The cryostatic stability criterion to which the conductors are designed requires that the superconductor not exceed its critical temperature even in the event of a complete current transfer from superconductor to the adjacent stabilizer. In addition, all the conductor within the winding is designed to operate in the high field region of the winding even though the field experienced over most of a section 1s substanlially lower. Furthermore, when a normal region is sensed and the dump switch between winding and coil is opened, a partial decay in the operating current occurs through dissipation of energy in the normal region and the dump resistor. This in turn, is a stabilizing factor.

A preliminary list of the instrumentation that may be necessary for the Base Load system is given in Table $V-I$. The instrumentation will be used to monitor the external cryogenic support system, the power supply, and the winding. The various types of instrumentation listed serve a protective as well as diagnostic function in the system. Many of the items listed would be used solely during the cooldown of the system to assure temperature gradients within allow:ble IImics.

POTENTIAL AREAS FOR $R \& D$

During the course of the study an overall impression was developed of the state of the art in superconductivity, cryogenics, structural materials, structural design and fabrication techniques. This overview, together with the reference design development, allowed specific areas and problems relevant to superconducting MHD magnet system design, contruction, and operation to be identified. Some problems which may arise and require independent $R \& D$ effort, either theoretical or experimental, before a full-scale base load superconducting magnet fabrication is undertaken are discussed below.

\section{CONDUCTOR FROFERTIES AND ETARILITY P.EQUIREMENTS}

\section{Requirements for Stability}

A general investigation into the necessary and sufficient conditions for cryostatic stability is needed as well as a study of the potential sources and magnitudes of distrubances (i.e., de-stabilizing influences) in magnets of this size. In most designs based on cryostatic stability, it is explicitly or implicitly assumed that the helium gas generated in the vicinity of a disturbance may be vented and readily replaced by "fresh" helium. The ability of the helium to be vented and replaced, however, is strongly dependent on the geometry of the situation. For circuitous helium paths usually incorporated in magnets, the assumption is probably valid for small disturbances (which are also stabilized 
I. Mugnet

A. Coil Telemetry

1. Magnetic field

2. Layer-to-Layer Voltage

3. Conductor Curre nt

4. Conductor Tenperature

B. Pover leàds

1. Fositive Current Lead Tenderature

2. Positive Current Lead Voltage

3. Positive Current Lead Gas Flow Rate

4. Hegative Current Lead Temperature

5. Regative Current lead Voltage

6. Negative Currerit Lead Gas Flow Rate

c. Cryogenics (Internal)

1. Liguid helium Level Indicator (Service Stack fesarvair)

2. Vent system fressure

3. Vocuum Pressure

D. Structure

1. Rádiation Shield Temperature Sensor

2. Rádiation Shield Strain Gauges

3. Radiation Shieid Proxinity Sensors

4. Cold Structuie Tomperature Sensors

5. Cold Structure Strain Gauges

6. Garm Eore Strain Gauges

7. Rooin Temperature Deviar

8. Supoort Column Strain rauges

II. Power Supply
1. Voltage indicator
2. Current Indicator
3. Internal Circuitry Temperature Sencors
4. Dump Suitch Siatus indicator
5. Dump Resistor Voltage
6. Dump Resistur Tenperature
7. Ground Fault Sensor

ili. Cryogenic Support

1. Liquefier/Refrigeiator pressure Sensor

2. Liguefier/Refrigerator lemigrature SErsor

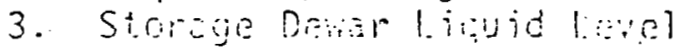

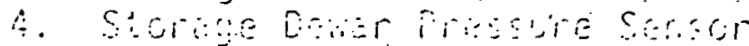

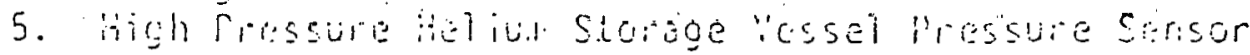


by multi-dimensional conduction effects) but not valid if a large region were to be affected. It is unlikely that replacement of helium can occur if large regions are involved; hence the local or "stored" helium immediately available dominates the situation. Large magnets can probably be desigred, built, and reliably operated vithout a thorough understanding of the size of likely disturbances and of efficient means to achieve stability if sufficient conservatism is employed. However, a thorough theoretical and experimental investigation in this area would achieve considerable savings in material for large magnets in MHD as well as other areas.

Impact of High Current Conductor on System Cost

If the operating current for the system is raised, the conductor necessarily becomes larger. The result is that the conductor is more difficult to fabricate, however, the total length required is reduced and the net impact on the cost of the conductor for the system is not clear. The larger conductor is more diff1cult to handle during coil fabrication, however, fewer turns are necessary and the net impact on winding cost is not obvious. The higher current requires larger vapor-cooled leads and Induces more boiloft, which increases the cost of the cryogenic support system. However, the higher current system should be somewhat easier to protect because of the lower inductance. In view of these offsetting effects, a detailed investigation is required to determine the net effect on system costs.

High Current Conductor Fabrication and Test

The base load magnet system will require an unprecedented quantity of conductor with a size corresponding to tens of thousands of amperes of currentcarrying capacity. A detailed fabrication analysis would be desirable to determine the cost effective approach to the large quantity, high current conductor production required. Consideration should be given to the composition of the basic billets, whether or not cabling is desirable, type of cable, yield, substrate shape, substrate composition, means for final conductor assembly, lengths cf final conductor, conductor transportation, and production schedule.

Support for Final Conductor Design

The heart of the magnet system is the superconductor, and the successful operation of the system depends on a thorough understanding of the electromagnetic, thermal, and mechanical properties of this component. Candidate conductor configurations may be chosen for reference design purposes on the basis of engineering calculations and published data. However, in the process of final design, experimental work in the following areas should be considered:

a. measurement of critical current and field characteristics at operating temperature,

b. mcacurement of the effect of stress nn r.ritical properties,

c. measurement of the stress-strain relationship for the conductor and determination of the modulus of elasticity,

d. verification of the thermal characteristics in a model of winding and cooling passages to assure satisfaction of cryostatic stability requirements, 
e. fabrication of sample joints, measurement of structural properties of the joints, and verification of stability of operation, and

f. measurement of thermal contraction coefficients for the composite conductor.

\section{IVINDING GEOMETRY AND CHARACTERISTICS}

Winding Mechanical and Thermal Characteristics

The windings in the magnet system will consist of a combination of many materials with vastly different mechanical and thermal contraction characteristics. Because of the large size, the thermally-induced stresses can be very large and may lead to problems in yield or failure when the additional stresses due to the electromagnetic loads are added. Measurements and analysis of the mechanical properties and thermal contraction characteristics of scaled-down models of candidate winding and structural configurations may be highly desirable.

Mock Winding Fabrication

The saddle geometry is complex and will require extensive tooling for the wincing process. The proper design of the tooling combined with evaluation of fabrication techniques can lead to considerable economic savings during the construction process. Because of the large size involved, the tooling will be a major expense; consequently, modeling of different facets of the construction process and items of tooling may be justified. As a minimum, practice winding with ordinary copper conductor sections should be utilized, to de-bug the final tooling setup. If structure is to be an integral part of the winding bundle, the tooling is that much more complex and evaluation of fabrication techniques that much more important. This program should extend beyond the winding stage to a phase involving fabrication and assembly of sections of dewar and support structure to be integrated into a full-scale model of a portion of the system. A development program involving design, construction and test of successively larger magnets would then be possible.

\section{JOINTS}

Estimates indicate that resistance of the order of $10^{-10} \Omega$ would be desirable in the system to keep the total heat generation by joints at a tolerable level. Experience with joints for the large conductors envisioned for this program is very limited. Hence a coordinated program involving joint fabrication and test appears necessary.

\section{HIGH CURRENT VAPOR COOLED LEAD DESIGN}

The vapor cooled leads which will be required for this system will most likely be required lo uperate at a higher sready current level than any utilized to date. A study and optimization of this component in light of different cooling options and the means for integration with the system should be undertaken. This should include consideration of cooling via boiloff helium, heat intercept stations, heat exchanger design, and terminal connections at warm and cold ends. Heat intercept stations could be based on the use of bulk liquid nitrogen on a return gas loop to the main liquefier system or on an independent refrigerator. 


\section{INSULATION CHARACTERISTICS}

The choice of the electrical insulation for use on the conductor is critical in view of the high internal loads which may be expected in the windings for systems of this size. An insulation must be chosen to satisfy voltage requirements and to have sufficient mechanical strength. Data are generally not available for candidate insulating materials at cryogenic temperatures; consequently, a program of direct measurement is necessary. As a minimum this should include mechanical properties, voltage breakdown strength and thermal contraction. In addition, it may be desirable to assemble sample lengths of conductor and insulation to assess handing characterisitics and the tooling necessary for insulation application during magnet construction.

\section{LOADS AND STRUCTURAL SUPPORT}

Transverse and End Turn Structure.

The loads of electromagnetic origin when the magnet is charged appear as hody forces distributed over the current-carrying portions of the winding.bundle. Computer programs exist for calculating these forces and their location to a degree of accuracy limited primarily by the amount of computer time expended. Once the forces are known, they are the input for structural analysis. The latter may be divided into two regions: (1) a transverse sect1on of the magnet far from the end turns and (2) the end turn regions of the magnet. The standard mathematical tools available to carry out a thorough analysis in these two regions are very limited; hence numerical methods are essential.

A need exists for development of efficient programs based on finite element analysis for the transverse structural design and end turn structural design. The nonhomogeneous and anisotropic characteristis of the analysis programs exist and, with modification, would be suitable for determination of stress and strain distributions in a transverse section. For the end turns, the problem is three dimenslund; cunsequently, analyoic ie more diffistilt and limited primarily by the computer storage lecessary and the largc time consumed in calculation. Extensive development aimed at more efficient calculation is necessary and warranted because of the large size and energy involved in the system.

\section{Thermal Stresses}

Fn1.1nwing an analysis of the stress and strain distributions due to forces of em origin, an analysis of thermally-induced stresses during cooldown is necessary. The scale of the devices of interest and the capital investment involved demand complete analyses and understanding prior to commitment to cunstruction.

Effects of Reaction Location and Assembly Gaps

The stress and strain distribution which will result in the system is dependent on the applied. loads and also on the location of reactions and gaps between components due to fabrication and assembly tolerances. An extension to the reference design results would involve evaluation of the impact of these items. 
The em load distribution and, in turn, the stress distribution at the corners of racetrack or saddle-type coils will be dependent on the magnitude of the radius. This effect could be investigated in conjunction with stress concentrations at connectors between structural components since this represents an extension in more depth to the reference designs which have been generated.

\section{Gravitational and Environmental Loads}

The base load magnet system will involve the support of an unprecedented cold mass. It is necessary, then, that the means for gravitational support be investigated in detail and optimized in terms of the means for interception of ambient heat load. An analysis of the system to assure stability relative to earthquake-related phenomena rould be desirable.

FAULT CONDITIONS, INSTRUMENTATION, CONTROLS AND INTERLOCKS

Fault Conditions and System Protection

Because of the large energy stored and large cryogen requirements of the system, a study involving cryogenic and electrical fault conditions is essential. This should include: (1) loss of coolant supply to the main magnet, heat intercept stations and/or vapor cooled leads; (2) loss of vacuum; (3) structural: failure; (4) load redistribution due to short circuits; (5) loss of power input to the power supply; (6) circuit breaker failure to open (close) during startup or shutdown under normal or emergency conditions; (7) drop in liquid helium level in the main dewar.

Component Mockup.

At the design of the magnet system and MHD plant evolves, requirements for initial startup, operation, controls and safety will become solidified. During this period areas requiring analysis and breadboard mockup will arise. Experimental eveluation of alternates may be desirable.

\section{TNTFRFAC.F. PROBT.FMS}

In the course of developing the final plant design, the interface requirements for the magnet system and all other components will be investigated in detail. These are prime areas for development of problems requiring additional $\mathrm{R} \& \mathrm{D}$. One potential problem area is the stray field from the magnet system. Its effect on other MHD plant components, or instrumentation, and on controls must be investigated in detail.

The purpose of the above discussion was to outline some of the areas in which $R \& D$ may be necessary before construction of the MHD magnet system begins. The capital investment required demands investigation of the problems of this type and the time scale envisioned for MHD system development demands that investigation be initiated immediately. 
Joints

Joints between superconductors have been developed and used in magnets for many years. The most commonly used geometries are the lap, scarf, and butt joints.

In the lap joint the conductors are overlapped (several inches to several feet depending on conductor size, established group practice, and design philosophy) and then clamped in a fixture while the joint is formed. The scarf joint begins as a lap joint; however, material is removed from the sections indicated after the joint is made. The basic advantage of the latter over the former is that a scarf joint will have the same cross sectional dimensions as the main conductor and may, therefore, be wound more easily into the coil.

The butt joint is seldom used except for special applications. If the conductor is a multifilament material in a matrix, of copper, for example, then the butt joint is the only one of the three in which expused superconductor may be joined to exposed superconductor with the potential existing for a true superconducting joint. Overall critical properties are usually degraded because of the extreme difficulty of aligning and fusing all filaments in the matrix.

Joints are usually not superconducting. With proper design and technique, however, resistances in the $10^{-8}$ to $10^{-9} \Omega$ range are common. Consideration of the heat generated in these areas is accounted for in the magnet design.

Joining methods which have been used fall into the following categories:

1. soft solder

2. silver solder

3. compression

4. ultrasonic welding

5. cold welding

6. explosive bonding

The use of soft solder in lap or scarf joints is probably the most common technique for conductors of all sizes. Conductor ends are usually cleaned, tinned, clamped in a fixture, soldered, machined (if a scarf joint), cleaned, and then insulated. For very large conductors, control and application of sufficient heat may be a problem area. Furthermore, soft solder is not a structural material, and joint support must be considered in the design and coil fabrication.

Attempts at using silver solder in the joining process have been largely unsuccessful because the high temperature and relatively long time involved at temperature have degrading effects on superconductor critical properties.

Compression joints in which two conductors are bolted together with a relatively soft material (e.g., indium) in between have been used primarily in cases where disassembly must be accomplished while the system is cold. This has 
been successfully used at the juncture between coil leads and vapor-cooled power leads where the latter are removable but is not popular within windings where it is electrically and structurally more conservative to solder the joint.

Ultrasonic welding offers a great deal of promise and was used in joints for the $\mathrm{U}-25$ bypass magnet which was fabricated at the Argonne National Laboratory. Structural and electrical resistance checks on joined samples have been excellent; however, considerable effort is required in fixturing and tuning the apparatus. Utilization of the techniques on the large conductors expected to be used in this program will require some development. However, the technique is attractive because of its ability to be controlled exactly once debugged.

Cold welding has been used effectively for small conductors in applications where a superconducting joint is highly desirable and some degradation in overall critical properties may be tolerated. It basically consists of forming a butt joint under extreme axial pressure. For large conductors considerable development would be required, and it is unlikely that the advantages of this method would outweigh others which are more promising.

Explosive bonding is a technique which is under development and has exhibited promising results. ${ }^{2}$ In essence, a lap joint is formed under the extreme pressure provided by a shaped explosive charge.

For on-site fabrication in magnets of the size anticipated, the most promising techniques for joint formation appear to be ultrasonic welding and explosive bonding. Development would be necessary in each case. A third possibility would involve the popular soft solder method. In any case, development of adequate quality control procedures will be essential.

Magnetic Field and Force Calculations

The total force on a section of current carrying conductor(s)--for example, a portion of a magnet winding--may be found by integrating the Lorentz force over the volume of the section of interest. To obtain an analytical result in closed mathematical form, it must be possible to perform the following operations in the region:

\section{Express $\overline{\mathrm{J}}$ mathematically \\ 2. Express $\bar{B}$ mathematically \\ 3. Integrate $\overline{\mathrm{J}} \times \overline{\mathrm{B}}$.}

The procedure outlined by steps 1,2 , and 3 is tractable only in situations with particularly simple geometry. In most cases, one or more of these steps must be replaced by au appruximating procedure.

For the saddle geometries, all of the above steps must be carried out numerically. The basis for the computation is that it is possible to express in closed form the magnetic field generated by a straight current filament of finite length. The above procedure is then replaced by: 
1. Represent the entire current carrying winding by a model composed of urrent carrying "sticks" of finite length. This requires a specification of the end points of each stick in a suitable coordinate system and of the magnitude and direction of the current carried by each stick.

2. Select the coordinates of points at which the magnetic field is to be determined and calculate the field at each of these points by a vectorial sum of the contributions from each current "stick." If a point lies outside the winding model, then contributions from all of the sticks are summed. However, if a point is located on a stick (as is necessary if the goal is the determination of the force at that point), then it is necessary to sum all contributions except for that duc to the stick which passes thorugh the point of interest. The latter is necessary to avoid the fact that the zero cross-sectional area of a given stick together with ito finite ourront laads to an infinite magnetic field on the stick itself.

3. Letermine the Local components of the force per unth vulume at a given point by forming the vector cross product of the current carried by the stick and total magnetic field calculated at that point and dividing by the winding cross-sectional area which the stick represents.

4. Find the total force in a selected direction on a section of winding by summing the proper components of the forces per unit volume multiplied by the incremental volumes they model over the section.

In general, the larger the number of sticks in the current filament model, the better the approximation; however, computational time increases rapidly and even the initial task of merely specifying the coordinates of the sticks may become formitiable.

Several computer programs are available at MCA which facilitate the construction of the current stick model of the windings and which allow fields and forces of electromagnetic origin to be computed. The output from the above programs must then be utilized in a detailed finite element analysis to arrive at distribution of stress and strain. These analytical tools are not well developed for saddle magnet design and represent an important area for further investigation.

The use of two- and three-dimensional finite element computer codes in the design of the large magnets anticipated is essential. Computing time and storage required may be expected to result in long expensive runs.

Structural Materials

a) Summary

After a brief review of the potential structural materials that are available for use in this application, the following conclusions have been drawn. 
a. 310 stainless steel has been chosen as the material for structural components at cryogenic temperatures. The main reason for the selection of this material is the fact that it has similar prior applications, has not shown signs of undergoing austenitic transformation at. $4{ }^{\circ} \mathrm{K}$ during tests, and has favorable manufacturing and strength characteristics.

b. 5083 aluminum has been chosen as the material for structural components at room temperature. It exhibits the best overall strength and manufacturing characteristics of the candidate materials considered (i.e., stainless steel, aluminum, and titanium).

c. Composites will not be considered as candidate materials for main structural components because: the application does not necessitate their use (i.e., low weight, although desirable, is not a requirement), compiled data to date does not adequately characterize composite materials for design properties at low temperatures, and they have fair to poor manufacturing characteristics compared to metals for large components using present-day technology. Composites are an area which requires further developmental work unless they are usec in simple geometric forms with simple loading patterns.

b) Introduction

Considerable information is available for many metals concerning general mechanical and physical properties at cryogenic temperatures. Some metals and most composite materials of present and future interest are, however, inadequately characterized for full confidence in selection and utilization in large-scale cryogenic applications. This is especially true for materials other than metals such as ceramics, metal and epoxy matrix composites, fiberglass, plactics, and superconducting elements themselves. The general areas in which information is scarce include:

a. Effects of materials processing techniques (both in commercial practice as well as new developmental approaches) on froperties at cryogenic temperatures generally have not been evaluated or well documented.

b. Effects of fabrication and joining processes (both in commercial practice as well as new developmental approaches) have been a similarly neglected area.

c. Available cryogenic materials property data of ten do not extend to liquid hydrogen or to liquid helium temperatures.

d. Long-term effects such as fatigue and creep have not been thoroughly investigated.

e. Standardized design codes need to be continuously reviewed and updated to allow for changes in design criteria levels to account for property variations with temperature. 
Additional cryogenic material property research is underway but may or may not be keeping pace with. the development of new, potentially useful materials, particularly composites,

The structural materials for use in this program fall into the category identified as static support and/or containment structure; i.e., normally low to moderately stressed and subjected to static loads. For this application there is adequate cryogenic materials data compiled presently on metals to allow material selection for main components with a high degree of confidence. This is not the case with composite materials and other non-metals. In future design phases for magnets of the type of interest to this program, material selection will be of prime importance and will require a supporting effort involving material property verification and component mock-up and test. Under this program, a preliminary materials survey was performed and materials tentatively selected to allow the design process to be carrled forward. Results are subject to review and change as a final design develops.

Cryogenic Structural Applications

Certain metals show a marked decrease in ductility with decreasing temperature. The extent to which the ductility is lowered depends largely on the crystal structure of the material, on the alloying conditions, and on the stability of the metallurgical state. Table $\mathrm{K} 2$. shows room temperature and cryogenic temperature properties for a selected list of materials. They were chosen as likely candidates obtain typical properties for use in the srructural eslimales to be performed under this program. As the final system design is approached, detailed specifications will have to be developed for the materials to be used. In Phase I of this program, cold structural weight estimates were generated assuming typical properties for stainless steel and for aluminum.

A brief review of presently available property information at $4.2 \mathrm{~K}$ leads to a choice of $310 \mathrm{~S}$ stainless steel. It is one of the most stable of the austenitic stainless steels. Others may undergo a transition to a less duct1le condition. In addition, the $310 \mathrm{~s}$ has an (integrated) coefficient of thermal expansion that is closet among the candidate materials" to that of OFHC copper.

More information would be desirable on the aluminums; however, a choice at present might lead to a 5,000 or 6,000 serles alloy in view of better low temperature ductility following welding. The latter will no doubt be required in forming built-up structural sections.

Cèrtain alloys of titanium have promising low temperature characteristics; however, more data 1 s required. Fabrication charactcristics are generally less desirable than with the stainless steels or aluminiums, and the material tends to be considerably more expensive; hence it was not used in the Phase I design estimates.

Room Temperature Structural Applications

Material property information is much more readily available for candidate materials at room temperature. The major structural member in this category is the room temperature dewar shell which is, basically, a vacuum-tight pressure vessel. 
TABIE V-2-TYPICAL MECHANICAL PROPERTIES OF VETRLS

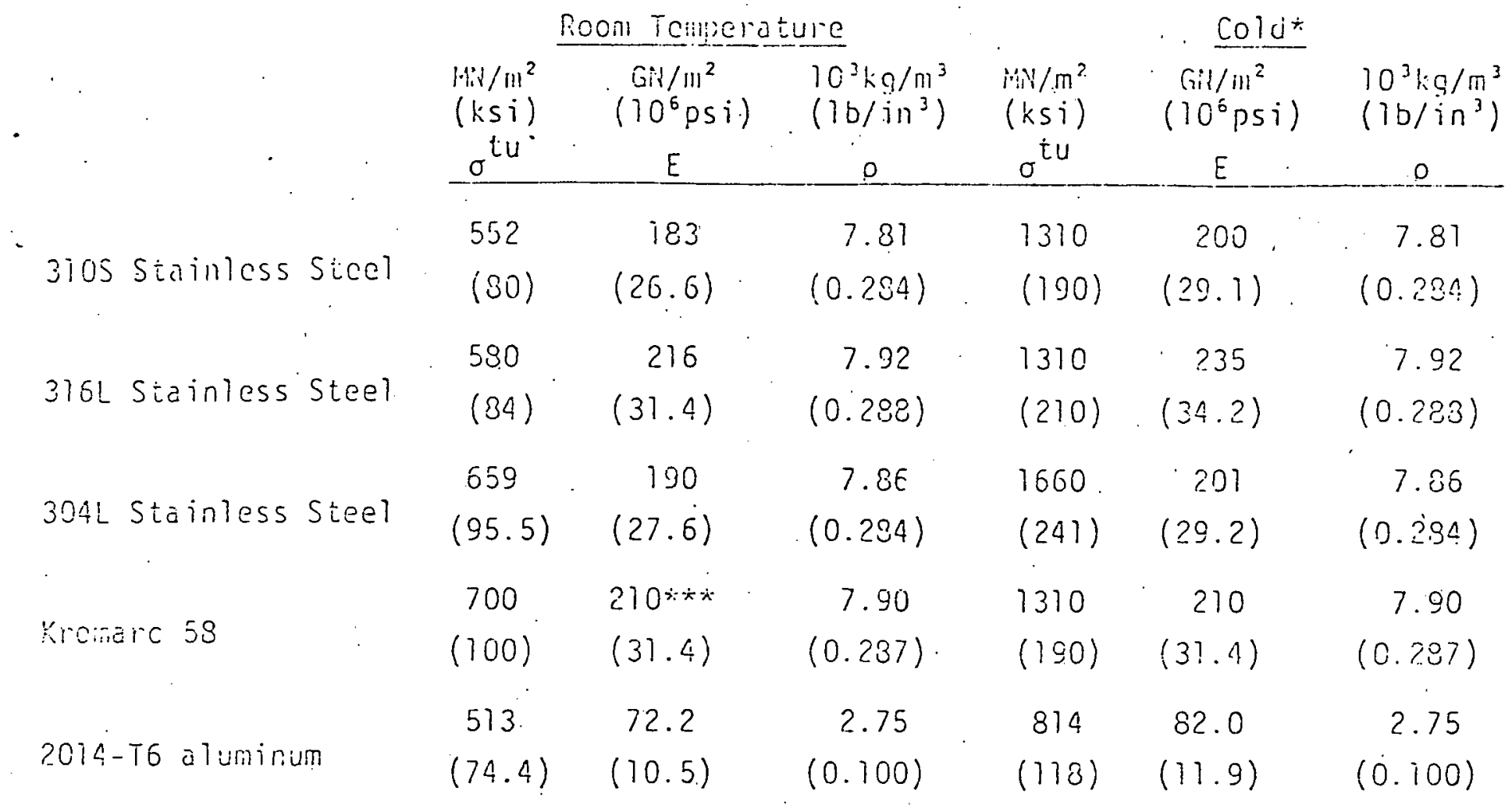

.083 a 7 uninumi:*:

$5086-134$ a 7 uninum

$\begin{array}{llllll}338 & 68.7 & 2.75 & 577 & 82.8 & 2.75\end{array}$

(49)

$(10.0) \quad(0.100)$

(77) (12.0)

$(0.100)$

Ti 6 A T - $4 V(E L I) * * *$

862

(125) (16.0)

$4.26 \quad 1641 \quad 132$

4.26

$(0.155) \quad(238) \quad(19.1)$

$(0.755)$

* $4.2^{\circ} \mathrm{K}$ except as noted.

$\therefore$ cold data at $20^{\circ} \mathrm{K}$.

$\therefore$ ik estimated-specific data not availeble

hare: $\sigma^{\text {tu }}=$ ultinete tensile strength

$E=$ Yoing's lodulus of Elasticity

$\rho=$ méss density 
Because of the large size involved, there may be definite advantages to fabrication using aluminum. Estimates in Phase I however were based on both an aluminum and a stainless steel as alternates. General manufacturing, ayailability, and cost estimates lead to a tentative choice of 5083 aluminum or 304L stainless steel. 
VI. DESIGN CODES APPLICABLE TO LARGE BUBB̈LE CHAMBER MAGNETS

The list below includes codes and references, which are applicable to large bubile chamber magnet systems where systems includes the magnet, vessels, instrumentation and controls, etc. I am unaware that any single code has been developed specifically for the wagnets. Generally the procedure has been to state design criteria which must be met (BNL) or the characteristics, specifications, and conditions (FNAL) (ANL). A statenent of design criteria, characterisctics, specifications and conditions can be found in the respective Safety Analysis Reports.

Frequently, to meet design requriements, particularly for the magnets, each of wich has sone new or unique features, use is wade of properties of materials data which can be found in various references and applied as is judged by the designer (subject to review) to be approprißte.

\section{Cocies and References}

Naticnal Building Exit Code (National Fire Protection Association (NFPA) Stendard

NFPA Standard H101, "Life Sajety Code"

National Electric Code(NFPA)

American Society of Mechanical Engineers (ASME) Unfired Pressure Vessel Code, Section VIII.

ASME Nuclear Vessels, Section III

Interstate Commerce Commission (ICC) Regulations, Tariff "19

Safe Handing of Compressed Gases, Pamphlet P-I, Compressed Gas Association (CGA)

Compressed Gases Safe Practices, Pamphlet \#95, National Safety Council (NSC)

American Standard Code for Pressure Piping, ASA B31.1 and ASA B31.3.

Handbook of Compressed Gases, Compressed Gas Association

Reinhold Publishing Corporation, N.Y. (1.966)

Safety Guidelines for High Energy Accelerator Facilities, U.S. Government Printing Office, Washington, D.C.

A Compendium of the Properties of Naterials at Low Tenperature WADD Technical Report 60-56.

Selected Cryogenic Data Noteb̆ook, BNL

Safety Report 15-foot Bubble Chamber, NAL (1972)

7-foot Bubble Chamber Safety Analysis Report, BNL (1973)

The last two references contain the wost inforwation relating specifically to superconducting ivagnets. 
APPENDIX. EDITED EXTRACTS RELEVANT TO MED MAGNET DESIGN FROM: PROCEEDINGS OF THE WORKSHOP OF STRUCTURAL ANALYSIS NEEDS FOR MAGNETIC FUSION ENERGY SUPERCONDUCTING MAGNETS, M: REICH ET AL. BNL REPORT CONF. 760984/VC-20b

The most important stages leading to the manufacture of superconducting magnets are summarized in Figure 1. This procedure is typical of the general approach used the the present day contruction of fission reactors and other types of large complex structural devices. The design stage is the

first part of the process. It is highly dependent on the function of the device under consideration and on the available material. The second step is the analysis stage where the design is evaluated with respect to its response to structural, thermal, and fluid, etc. induced loads. Step three involves using the results of the analysis to evaluate the safety of the design One way of doing this is to compare the analysis results either to the yield stress of a one-dimensional specimen or to the failure stress or failure strain of a one-dimensional specimen.

Another approach is to compare the analysis results to certain standards. For instance, fission reactor designs are compared to the ASME and NRC standards. If the standards are satisfied, we can proceed with the manufacturing process. If, on the other hand, the standards are not satisfied, we must return either to the design stage and redesign the device or perhaps to the analysis stage and carry out a more in-depth analysis using a more sophisticated method; for instance, carrying out an inelastic analysis instead of an elastic analysis. This is, in fact, the case in many instances when the ASME and NRC standards are used and found not not to be satisfied by elastic methods but can be satisfied by the more sophisticated inelastic analysis. The aim of the analysis should be to determine the structural response of the magnets. In order to analyze the problem we need a precise description of the geometric configuration. This should include weldments, flaws, and other things that could affect the geometry. We need to know the normal as well as the upset loads that the device will experience throughout its operational life. As indicated on the right hand side of Table 1 , static, cyclic, dynamic, magnetic, thermal and earthquake loads, etc. must be known and accounted for in describing the possible input conditions. Thirdly, there are the material properties of all components comprising the superconducting magnet composite. When considering upset and quench conditions, we need to know melting properties, while normal operating conditions involve properties at $4 \mathrm{k}$. Since conditions can exist anywhere between these extremes, we require a range of material properties that vary from $4 \mathrm{~K}$ to melt. As shown in Table 1 these properties include elastic properties, elastic-plastic properties, fatigue properties, fracture-mechanics properties, thermal properties, and electrical properties. The preceding properties are usually obtained from one-dimensional tests. However, since we are dealing with multi-dimensionally stressed structrues, it will be necessary to obtain some relationship for the above mentioned materfal properties that takes into account this mutual interaction.

The most extensive technique in use for structural analysis of these highly complex structures is the finite element method. As shown in Table 2 these methods are available for elastic, elastic-plastic, fracture, and failure behavior. For a well-designed structural system, the design aims are that the operational stresses remain in the elastic zone. For these cases, all that is needed is an elastic code that would give statlc and dynamic type of analysis, preferably two-dimensional 
SUIWARY OF IMPORTANT STAGES LEADING TO MaNUFACTURING PROCESS OF MAGNETIC FUSION ENERGY SUPERCONDUCTING MAGNETS

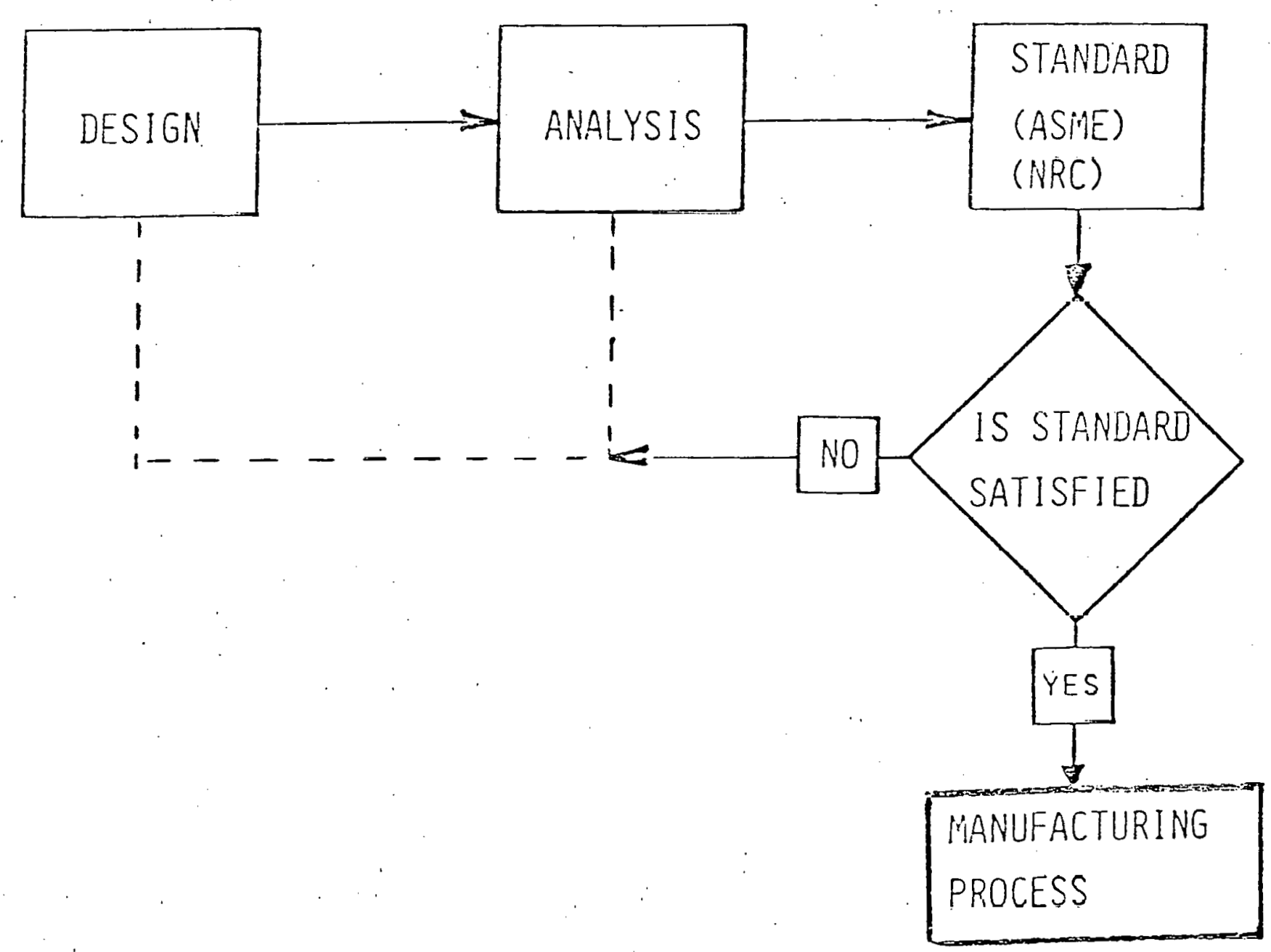

Figure 1 
TABLE 1 - INPUT NEEDED FOR THEORETICAL ANALLYSIS OF THE STRUCTURAL RESPONSE OF SUPERCONDUCTING MAGNETS

1) Geometric configuration

Include fabrication effects, weldments, flaws, etc.

2) Normal and upset loads

Static, cyclic, dynamic magnetic loads, experiences throughout thermal loads, earthquake loads, etc.

3) operation life

3) Material properties

a) Elastic

b) Elastic-plastic

e). Thermal

from $4^{\circ} \mathrm{K}$ to melt

c) Fatigue

f) Electrical

d) Fracture

g) Multi-axial

Relationships

TABLE 2 - COMPUTED CODES IN CURRENT USE FOR ANALYZING COMPLEX MECHANICAL STRUCTURE'

(Note: The most extensive technique in use today is the finite element.method.)

\begin{tabular}{|c|c|c|}
\hline $\begin{array}{c}\text { Code } \\
\text { Designation }\end{array}$ & & $\begin{array}{c}\text { Analysis } \\
\text { Type }\end{array}$ \\
\hline $\begin{array}{l}\text { NASTRAN } \\
\text { MARC } \\
\text { SAP TV } \\
\text { SAFE-3D } \\
\text { ANSYS }\end{array}$ & 1) & Elastic \\
\hline $\begin{array}{l}\text { MARC } \\
\text { NONSAP } \\
\text { ANSYS } \\
\text { BERSAFE }\end{array}$ & 2) & $\begin{array}{l}\text { Elastic- } \\
\text { Plastic }\end{array}$ \\
\hline $\begin{array}{l}\text { MARC } \\
\text { NASTRAN } \\
\text { NAGIC } \\
\text { BERSAFE }\end{array}$ & 3) & $\begin{array}{l}\text { Failure } \\
\text { a) Fracture } \\
\text { mechanics } \\
\text { (grossly elastic } \\
\text { and inelastic) } \\
\text { b) Fatigue } \\
\text { c) Large deformation } \\
\text { d) Buckling }\end{array}$ \\
\hline
\end{tabular}

\section{Loading}

Conditions Dimensions

Static

Dynamic

$2 \mathrm{D}, 3 \mathrm{D}$

Weli designed system

operating conditions

Static

Monotonic

Cyclic

Dynamic
2D, 3D Upset conditions

2D, 3D Safety Analysis: A controlling factor in design 
and three-dimensional. The two-dimensional computer codes cost very little to run compared to the three-dimensional codes. Names of some available elastic codes are listed in Table 2. These include the NASTRAN Code, the MARC and ANSYS Codes which are available for a fee, and SAP IV which is available from the University of California. The SAFE 3-D Code is an older code developed by General Atomic. It was used in fission reactor designs in the early 1970's. In addition, there are a host of codes which every organization has, for example, Brookhaven National Laboratory has its own; and other organizations like Grumman, McDonald-Douglas, etc. have their in-house developed elastic two-dimensional and three-dimensional codes.

There is a need for a code that can provide an elastic-plastic analysis for upset conditions and it should be capable of static, monotonic, cyclic, and dynamic analysis. Both two- and three-dimensional capabilities will be required because there are complex problems where three-dimensional stress conditions prevail. Codes that can perform elastic-pldstic analysis (ace Table 2) Include NONSAP, a public domain code which is available at a nominal fee from the University of Berkeley, Bersafe which is available from England at a fee, MARC, ANSYS and those from various organizations which lave their own variations. Safety analysis is a controlling factor in most designs and will require additional types of two- and three-dinensional computer codes to asses the merits of a particular design. Here we need fracture mechanics codes. If conditions are grossly elastic the types of codes listed in Table 2 are available; if not, a fracture mechanics code for grossly inelastic conditions will be needed. Such codes are not available except for some types of monotonic behavior. Methods to predict fatigue behavior are also needed. Complex three-dimensional problems involving materials controlled by local plastic overload conditions will require large deformation formulation and methods to evaluate failure and buckling phenomena. Some of the codes available for some of these analysis are shown in Table 2.

MARC contains some sort of fracture mechanics criterla. The salle is true for NASTRAN and IAGIC, which have versions capable of dealing w1th elastic fracture mechanics behavior. The English claim that Bersafe also has fracture mechanics analysis capability.

MHD magnets large and heavy in size carry large currents at magnetic fields up to $7 \mathrm{~T}$ and generate large forces and pressures. The systems operate near $4 \mathrm{~K}$ in a liquid helium bath of large volume. Sudden transitions from helium liquid to gas can produce pressure increases that have to be carried by the pressure vessels, which are double walled dewars, required to maintain vacuum for the low temperature cryogenic magnet system. Thus, the dewars are liable to be pressurized from a fraction of a torr to a very high pressure. This means that there are very large forces generated in operating and faulted conditions. The potential for some kind of a failure is there and the consequences of releasing so much energy in relatively. short times could be explosive. Operators and the public have to be protected from such hazards.

The magnets that have been built to date are comparatively small and whether or not the forces, thermal characteristics, etc. are scalable is not a foregone conclusion. The material data base needs to be extended. Some of the needed information is there, mostly, in the form of conventional material data which is available, but much more data is required. For instance, there are very strong magneto-elastic interactions that the designer does not have to take into 
account ordinarily when he performs, for example, the dynamic analysis for an earthquake. The standard dynamic procedure he goes through modeling an engineering structure as teams does not and cannot consider the saturation and instability effects that can be incurred due to the interaction between the magnetic and the inertia forces. Obviously such an analysis is not going to be valid. The realistic assessment of the structural, electromagnetic, cryogenic problems involves a large number of different disciplines in combination.

Designers and engineers like to be conservative. They add mass, for instance, increase the size of beams, they like to reinforce the structure by using higher strength materials, etc. In a conventional structure this usually works. However, for instance, where thermal gradients are generated, the addition of thickness is going to increase the part of the stress field that is due to the thermal gradients, while it may reduce some other stresses, due to pressure, mechanical load etc., thus the failure criteria cannot be evaluated by just looking at the stresses. The addition of mass is definitely deleterious for the thermal fatigue failure mode while the reduction of the average constant static stress, improves the collapse strength. 'The question of whether or not the design is made more or less conservative by the added material cannot be determined by an isolated stress value; it is necessary to explore the entire process of failure modes evaluation. The systematic set of steps by which this can be carried out is valuable in itself but more importantly it takes out the subjective aspects of the design development which is particularly necessary when the state of the art is pushed beyond what knowledge based on actual experience has been accumulated. Thus the drafting of some kind of coordinated design guide which to some, would seem as a restriction, would actually help in the development of useful research programs and would be particularly helpful in formulating the long-range data and analysis needs for these kins of structures.

An attempt to show how this can be done is illustrated by considering one aspect of the problem, i.e., that of stress analysis and strain evaluation. It is usual to specify some kind of allowable stress (usually geared to the yield strength) and allowable displacement and strain values for the superconductor. This is because part of the structure is very brittle and it doesn't take much conductor movement to destroy the superconductive state. Thus the computation of stresses has been going on in a conventional way for these various kinds of structures.

IHD coil systems may experience a relatively arbitrary set of load cycles throughout the life of the structure, including startups, shutdowns, some abnormal conditions, some scheduled, some upsets and perhaps a few emergencies as well. If the material itself is cyclically sensitive, one has to postulate either some kind of standard load history or an evaluation criteria is needed to compare the operating and design conditions since each different sequence could give you a different set of values.

Thermal conductivity is a function of the magnetic field strength. This is liable to change as a function of the number of cycles and magnitude of plastic strain. The thermal conductivity will influence the thermal stresses which, in turn, influence the thermal strain and hence influences the electric conductivity. These three interacting components have so far been evaluated as uncoupled loading 
components that can be superimposed but this may not be so. A sketch of the required properties of materials required to design magnets and estimate their performance in given in Figure 2. In actual practice these various characteristics operate simultaneously and cannot be isolated as shown in an analysis of behaviors. The chronology of the development of standards for the nuclear industry is given in Table 3 as a comparision to show the sequence of development.

Possible steps which can be taken now to develop magnet design standards are given in Table 3. First magnet design involves information on materials, analysis, and evaluation criteria. At some point fabrication begins and a need is developed for various welding procedures and quality control. The next step is installation, followed by startup then operation. This requires some kind of quality assurance techniques and this requires an in-serivce inspection. Codes or standards would be involved after the design analysis is completed and has to be evaluated to assess that it satisfies the projected lifetime. Reliable standards are needed for the installation. In a failsafe design there is no worry about what is happening during the operation, but in a safe-ilfe type of design, it is necessary to detect the approach of operating limits or malfunction perhaps to replace the components. It is possible to build something that doesn't have to stand up for the entire life, depending on what kind of inspection sensitivity and controls are exercised. It is also possible to detect an incipient failure instead of using the normal safety factors, which could be counter-productive in applications where the material properties and mechanical force fields are interacting. It is possible that such a standardization or criteria development would lead to a practical design rather than the one that has to start from time zero in a way that would be unchangeable.

A possible structure of development leading to appropriate magnet codes and licensing is given in Table 4. 
FIGURE 2 - CHARACTERTZATIOH OF MGHET MAERIALS IH

CRYOCEHIC TEMERATURE MANCE $294^{\circ} \mathrm{K}-l_{1}^{\circ} \mathrm{K}$

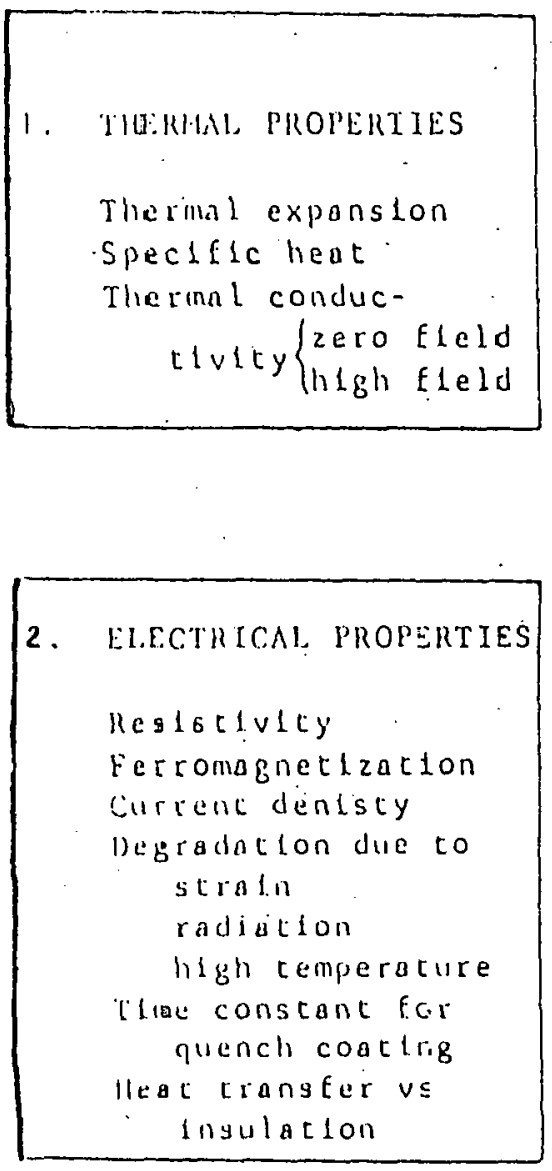

3. HECHAIICAL PROPERTIES

a. Elastic

Ycung's modulus

Stear's modulus

b. Elastlc-Plastlc

\begin{tabular}{l|l} 
Manotonic \\
Cyclic
\end{tabular}$\left\{\begin{array}{l}\text { stress } \\
\text { otrata } \\
\text { relations }\end{array}\right.$

Elongation, ductility Consticutive correlations

c. Faclgue and Fracture Crack growth rate litiblicycle, low cycle fatigue

Fraccure roughness $\mathrm{K} / \mathrm{c}, \mathrm{J}$

latlgue canage relations

Mulci-axial correlation

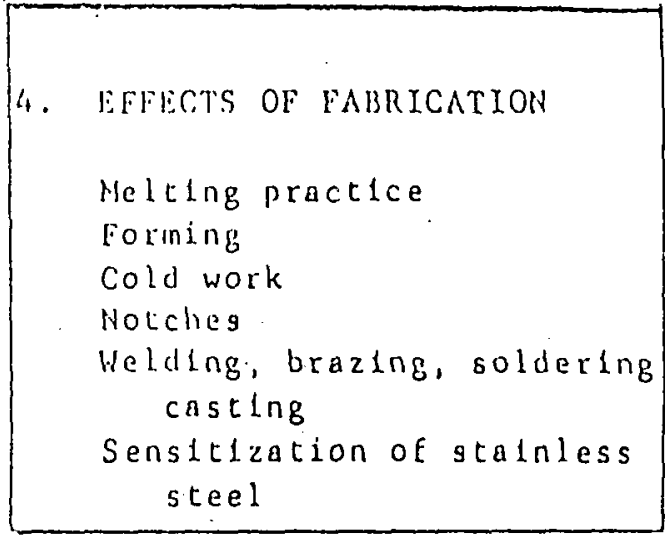

\section{NNALYTICAL MODELS}

Findte element for:

compostces

maguetle body forces

constitutive equations
6. EVALUATIOH STAHDARDS

- Tescling Spectlleation: Cryogente cesting me thods

Data base requlrement. Specimen, sengors

b. Deslgn Allownble Development

lintmuar Average properties

Deglgn. and safety factors

c. Non-destructlve tegt$\operatorname{lng}$

d. Qualley assurance nud Inspection 
TABLE 3 - CHRONOLOGY OF THE DEVELOPMENT OF STANUARUS FOR THE NUCLEAR INDUSTRY WI'EH SOME PARALLEL FOR SUPERCONDUCTING MAGNE:- DEVELOPMENT

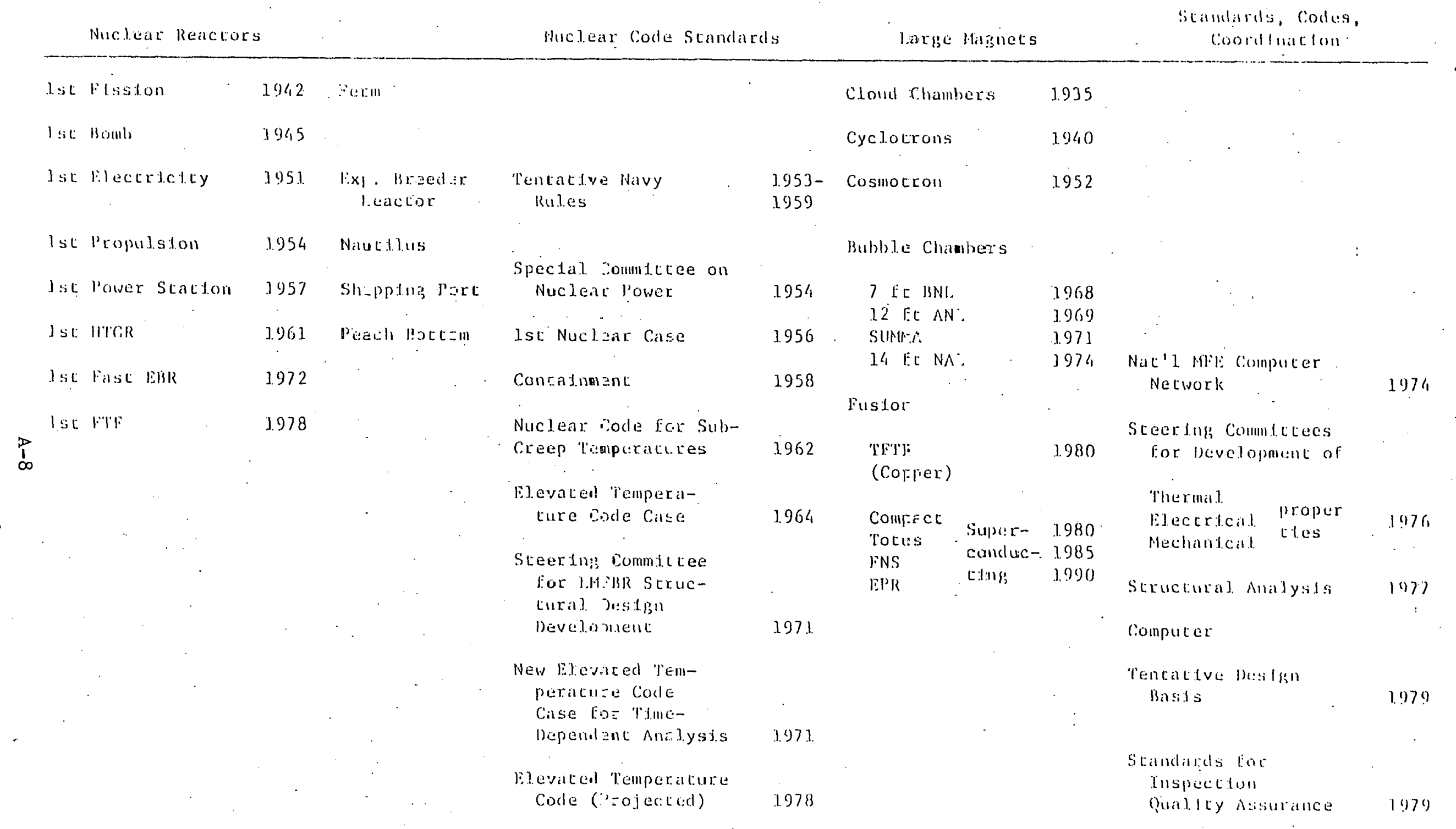


TARLE 4 -STRUCTURE OF DEVELOPMENT EFFORT

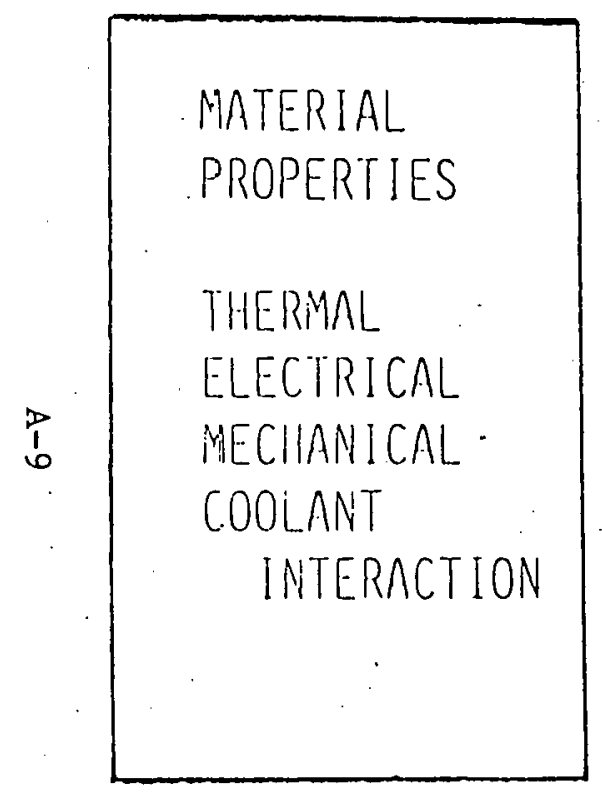

\begin{tabular}{|l|l|}
\hline \multicolumn{1}{|c|}{$\begin{array}{l}\text { COORDINATING } \\
\text { COMMITTEE }\end{array}$} \\
\hline $\begin{array}{l}\text { ANALYSIS } \\
\text { METHODS }\end{array}$ & $\begin{array}{l}\text { STRUCTURAL } \\
\text { BEHAVIOR } \\
\text { OTHOTROPIC } \\
\text { COMPOSITE } \\
\text { BODY FORCES } \\
\text { THERMAL } \\
\text { MAGNETIC } \\
\text { INTERTIAL } \\
\text { FAILURE MODES } \\
\text { CRYOGENIC } \\
\text { IMPULSIVE } \\
\text { HENTING } \\
\text { CONIDUCTOR } \\
\text { MOVEMENT } \\
\text { HE BOILING }\end{array}$ \\
\hline
\end{tabular}

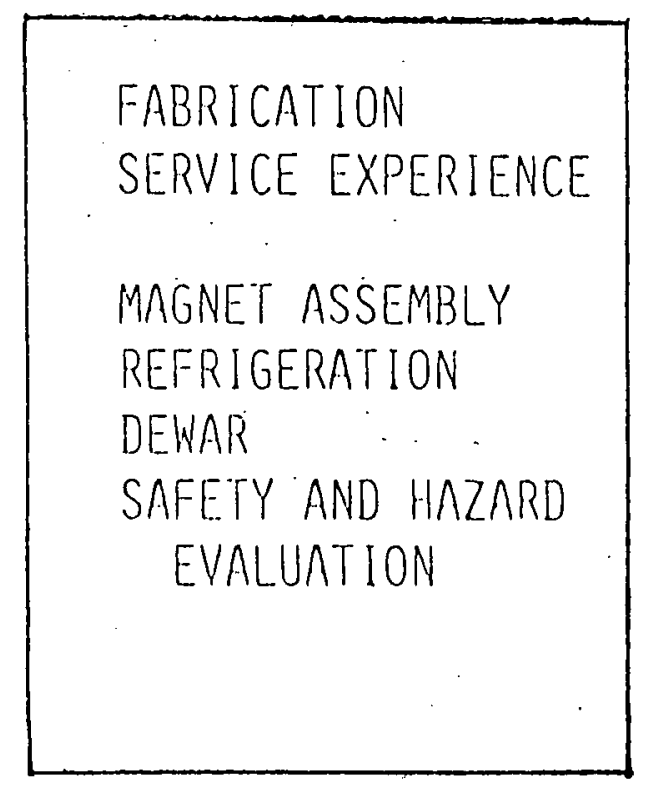
TENTATIVE DESIGN BASIS AND EVALUATION CRITERIA

\section{CODES STANDARDS} LICENCING ASSIST 